\title{
Ultra-Lightweight Cement
}

\author{
Sixth Quarterly Technical Progress Report
}

January 1 to March 31, 2002

Fred Sabins

Issued April 29, 2002

DOE Award Number

DE-FC26-00NT40919

Submitted by Cementing Solutions, Inc.

4613 Brookwoods Drive

Houston, TX 77092 


\section{Disclaimer}

This report was prepared as an account of work sponsored by an agency of the United States Government. Neither the United States Government nor any agency thereof, nor any of their employees, makes any warranty, express or implied, or assumes any legal liability or responsibility for the accuracy, completeness, or usefulness of any information, apparatus, product, or process disclosed, or represents that its use would not infringe privately owned rights. Reference herein to any specific commercial product, process, or service by trade name, trademark, manufacturer, or otherwise does not necessarily constitute or imply its endorsement, recommendation, or favoring by the United States Government or any agency thereof. The views and opinions of authors expressed herein do not necessarily state or reflect those of the United States Government or any agency thereof. 


\section{Abstract}

The objective of this project is to develop an improved ultra-lightweight cement using ultra-lightweight hollow glass spheres (ULHS). This report includes results from laboratory testing of ULHS systems along with other lightweight cement systems, including foamed and sodium silicate slurries. During this project quarter, comparison studies of the three cement systems examined several properties: tensile strength, Young's modulus, and shear bond. Testing to determine the effect of temperature cycling on the shear bond properties of the cement systems was also conducted. In addition, the stress-strain behavior of the cement types was studied. This report discusses a software program that is being developed to help design ULHS cements and foamed cements. 


\section{Table of Contents}

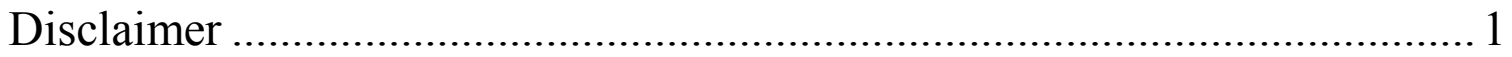

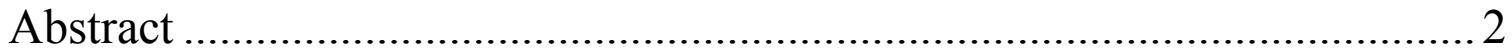

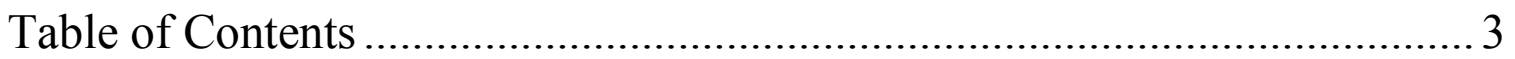

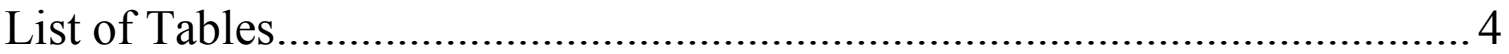

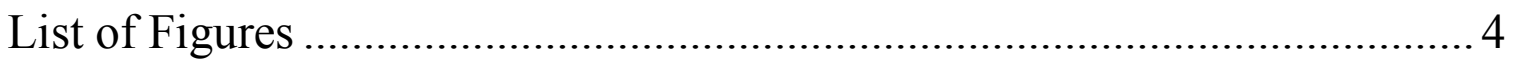

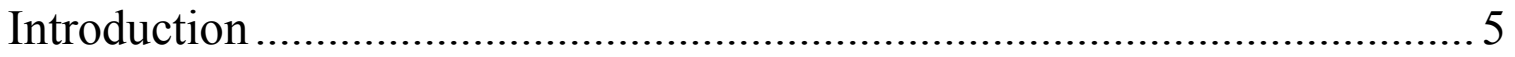



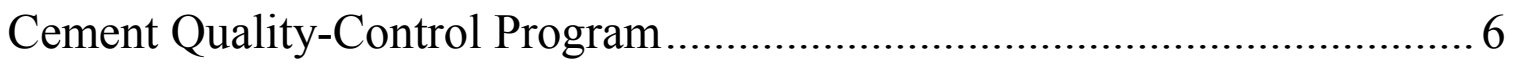

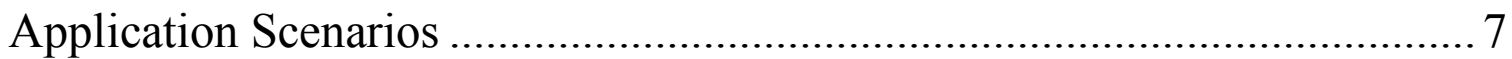

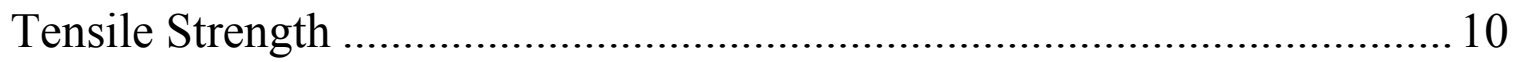

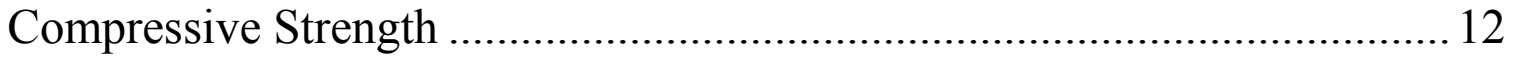

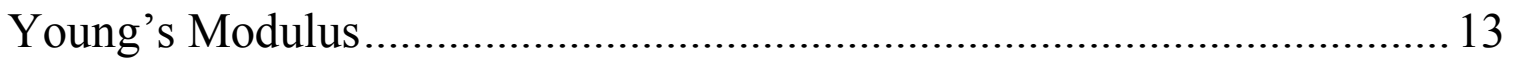

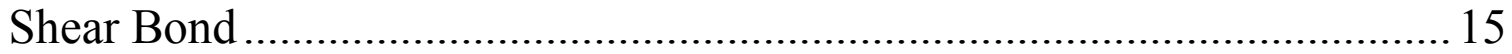

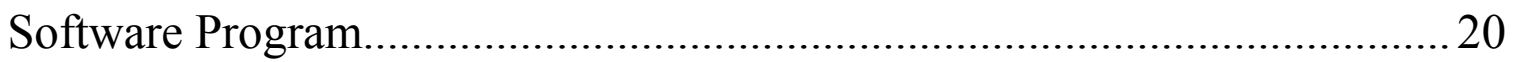

Plans for Seventh Project Quarter .............................................................. 26

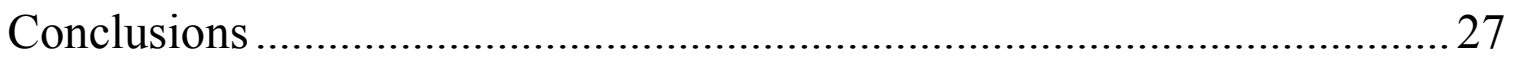

List of Acronyms and Abbreviations .........................................................28

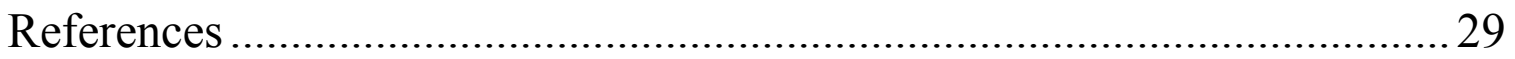



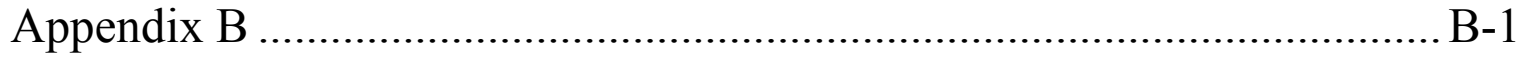




\section{List of Tables}

Table 1-Cement Slurry Compositions for Quality-Control

Testing Program........................................................................

Table 2-Percent $\mathrm{CaCl}_{2}$ for Low-Temperature Compressive Strengths .... 7

Table 3-Slurry Compositions for Application 2 Slurries........................... 9

Table 4-Tensile Strengths of Application 2 Cements................................. 11

Table 5-Tensile Strength Data for Temperature-Cycled

Lightweight Cements .............................................................. 12

Table 6-Compressive Strengths of Temperature-Cycled

Lightweight Cements

Table 7-Young's Modulus Data of Neat Class A and TXI

Lightweight Cements .............................................................. 14

Table 8-Young's Modulus Data of 11.5-lb/gal Lightweight Cements..... 15

Table 9-Shear Bond Strengths of Lightweight Cement Systems ............. 19

\section{List of Figures}

Figure 1-Sample orientation for ASTM C496-90 testing ......................... 10

Figure 2-Watertight container for temperature cycling............................. 12

Figure 3-Cross section of pipe-in-pipe configuration for shear

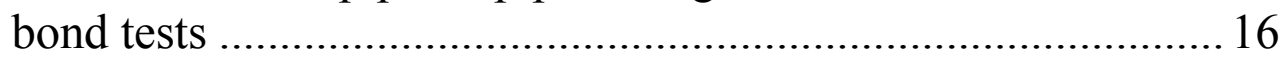

Figure 4-Cross section of pipe-in-soft configuration for shear

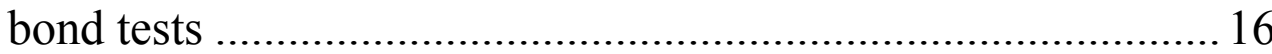

Figure 5-Configuration for testing shear bond strengths .......................... 17

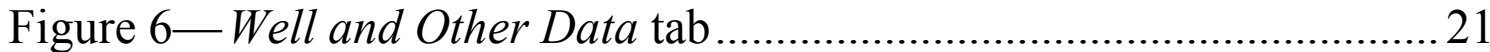

Figure 7-Lead Cement and Additives tab .................................................. 22

Figure 8-Drop-down menu for ULHS Type field ....................................... 23

Figure 9-Drop-down menu for Base Cement field ................................... 24

Figure 10-Drop-down menu for Units field............................................... 25

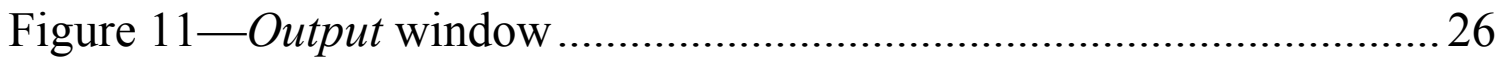




\section{Introduction}

Oilwell cementing involves placing a pumpable slurry of Portland cement, additives, and water into a wellbore. The slurry is pumped into the annular space between the borehole and a steel pipe (called a casing) that acts as a conduit from the reservoir to the surface. The cement sets in place (1) to support the casing in the hole, (2) to isolate various formations from one another, and (3) to control fluid movement within the well.

Typically, cement fluid density is anywhere from 12 to $17 \mathrm{lb} /$ gal. Certain conditions that require the application of low-density cements can be encountered during the well construction process. Lower density is required (1) to limit hydrostatic pressure on the formation, and (2) to prevent the formation from fracturing and imbibing the well fluid. This phenomenon, known as lost circulation, increases drilling and completion times and increases construction cost because of expensive remedial treatments. The upper sections of the well are where lost circulation most commonly occurs. These include surface and intermediate casings. Because formations covered by these casings are relatively close to the Earth's surface, application temperatures for these low-density cements are low.

The minimum practical density achievable with conventional cements and additives is approximately $11 \mathrm{lb} / \mathrm{gal}$. At this density, the slurry's stability and set cement's strength and permeability are only marginally acceptable. Water is the primary density-reducing material in these conventional cements. Additional water dilutes the cement, causing low strength and high permeability. Lower temperature, such as those in the upper well sections, delays strength development. To obtain lower cement density or greater cement strength, ultra-lightweight materials must be mixed into the slurry.

Ultra-lightweight hollow spheres (ULHS) are excellent candidate materials for producing ultra-lightweight cements. These small hollow glass beads effectively trap air in the slurry, thereby lowering the slurry density without the addition of water to the slurry.

This project is designed to develop cementing systems using ULHS through a carefully designed program of modeling, design, laboratory testing, and field testing.

\section{Executive Summary}

Laboratory testing during the sixth quarter was a continuation and extension of the testing that has been previously conducted. Testing compared slurries containing ULHS to foamed and sodium silicate cement systems. Comparison studies examined tensile strength, Young's modulus, and shear bond strength. Tensile strength testing during this quarter was performed using the ASTM C496 test method. Young's modulus data was performed using the ASTM C469 test method.

Testing to determine the effect of temperature cycling on cement system properties was also conducted. The compressive strength and shear bond strength of the samples that were subjected to temperature cycling were also measured. 
As a part of the project, a software program is being created to assist with the design of cement slurries made with ULHS. The program will also assist with the design of foamed cements.

Because of the large volume of cement required for this project, a quality-control process has been implemented. Information and data gathered for the program are presented.

Preliminary data indicates that the slurries made with ULHS performed very well. Further testing in future quarters will help establish performance qualities of cement slurries made with ULHS.

\section{Cement Quality-Control Program}

Because of the large quantities of cement used in the course of this project, an extensive quality -control (QC) program was initiated. Upon receipt, each bucket of cement is labeled with a materials log number and date. When a bucket is first opened for use, the date of opening is recorded in the materials log. This log number is referenced on the laboratory sheets for each test performed. Where applicable, tests are conducted according to API Specification $10 \mathrm{~A}^{1}$. Additionally, several tests tailored for the test conditions and materials (rheology and low-temperature compressive-strength development) are included in this QC program. API Specification tests and tests recommended by advisory board members were performed for the QC program.

The Class A and Class $\mathrm{H}$ cement performance requirements are presented in the original API Specification 10A (January 1995) before Addendum 1, which changed the free fluid procedure. The free fluid procedure used in these tests is the earlier version that uses graduated cylinders. Because the Lightweight Oilwell cement is not API cement, it is tested according to QC procedures developed by the manufacturer.

The physical requirements used to test each cement are listed in Table 1. Table 2 shows calcium chloride $\left(\mathrm{CaCl}_{2}\right)$ concentrations used at different temperature to accelerate the rate of compressive strength development at low temperatures. Calcium chloride was selected because it is one of the most effective and commonly used cement accelerators. 
Table 1-Cement Slurry Compositions for Quality-Control Testing Program

\begin{tabular}{|l|c|c|c|c|c|}
\hline \multicolumn{1}{|c|}{ Cement } & $\begin{array}{c}\text { Mix Water } \\
(\% \text { BWOC) }\end{array}$ & $\begin{array}{c}\text { Density } \\
(\mathbf{l b} / \mathbf{g a l})\end{array}$ & $\begin{array}{c}\text { Cement } \\
(\mathbf{g})\end{array}$ & $\begin{array}{c}\text { Water } \\
(\mathbf{m L})\end{array}$ & Test \\
\hline Class A & 46 & 15.6 & 772 & 355 & API Series of Tests \\
\hline TXI Lightweight & 75 & 13.2 & 541 & 406 & $\begin{array}{c}\text { Thickening Time \& } \\
\text { Compressive Strength }\end{array}$ \\
\hline TXI Lightweight & 105 & 12.1 & 426 & 447 & Free Fluid \\
\hline Class H & 38 & 16.4 & 860 & 327 & API Series of Tests \\
\hline
\end{tabular}

Table 2-Percent $\mathrm{CaCl}_{2}$ for Low-Temperature Compressive Strengths

\begin{tabular}{|c|c|}
\hline $\begin{array}{c}\text { Temperature } \\
\left({ }^{\circ} \mathbf{F}\right)\end{array}$ & $\begin{array}{c}\mathbf{C a C l}_{\mathbf{2}} \\
(\% \mathbf{B W O C})\end{array}$ \\
\hline 80 & 0.0 \\
\hline 60 & 1.0 \\
\hline 45 & 2.0 \\
\hline
\end{tabular}

These quality-control tests have been conducted to provide a baseline for each type of cement. This QC data will provide a basis of comparison for other data for this project. After several cycles of the complete QC program had been performed, the data showed no significant variations and remained within the vendors' specifications. Testing then proceeded with a less-stringent program of scheduled thickening-time tests. Each time a new bucket is opened, a thickening-time test is conducted. Additionally, a thickeningtime test is performed once a month on all opened buckets. The thickening-time test was chosen as a gauge to detect abnormal cement performance. Appendix A shows the QC program data gathered to date.

\section{Application Scenarios}

One way to gauge the performance of cements made with ULHS is to compare them to other ultra-lightweight cements. Members of the project advisory board decided to compare ULHS cements to foamed cement and a conventional sodium silicate slurry.

Sixth-quarter testing focused on a cementing scenario referred to as Application 2. Application 2 conditions simulated a typical land-based surface-pipe cementing job with the following conditions:

- bottomhole circulating temperature (BHCT) of $78^{\circ} \mathrm{F}$

- bottomhole static temperature (BHST) of $96^{\circ} \mathrm{F}$

- bottomhole pressure (BHP) of 1,000 psi 
As detailed in the first quarterly report, these conditions are average values obtained from Worldwide Cementing Practices ${ }^{2}$. Application 2 cement slurries were designed to achieve a thickening time of 4 to $6 \mathrm{hr}$ with $1.0 \%$ maximum free fluid.

Of the different ULHS classes studied in this project, 6K ULHS were chosen because they are able to withstand the hydrostatic pressures associated with the different simulation applications. The $6 \mathrm{~K}$ indicates that this class of ULHS has a crush strength of 6,000 psi.

Most tests were performed according to the API RP $10 \mathrm{~B}^{3}$ method. To adapt to ULHS and foamed slurries, some preparation and testing methods were modified. To minimize bead breakage caused by high shear from API blending procedures, mixing procedures were modified for the ULHS slurries. The following blending procedure was used for the ULHS slurries:

1. Weigh out the appropriate amounts of the cement sample and additives, water, and ULHS into separate containers.

2. Mix the cement slurry (without ULHS) according to Section 5.3.5 of API RP 10B. ${ }^{3}$

3. Pour the slurry into a metal mixing bowl and slowly add ULHS while continuously mixing by hand with a spatula. Mix thoroughly.

4. Pour this slurry back into the Waring blender and mix at 4,000 rev/min for 35 seconds to mix and evenly distribute the contents.

Testing methods for foamed slurries were also modified. For example, thickening time is performed on unfoamed slurries only. Because the air in the foam does not affect the hydration rate, the slurry were prepared per API RP $10 \mathrm{~B}^{3}$, then the foaming surfactants were mixed into the slurry by hand without foaming the slurry. This and the other nonstandard procedures for testing foamed cement are presented in Appendix B.

Table 3 presents slurry compositions for the 10.0 - and $11.5-\mathrm{lb} /$ gal slurries tested during this project quarter. To adapt each slurry to the application conditions and to meet the thickening time and free fluid requirements, additives, such as slurry extenders, accelerators, and foaming agents, were added to the slurries. The additives are widely available, generic additives, and are not specific to any particular service company. These additives include Witcolate ${ }^{\circledR} 7093$ (a foaming agent), Aromox ${ }^{\circledR} \mathrm{C} / 12$ (a foam stabilizer), Natrosol $^{\circledR} 250$ GXR (a fluid-loss control additive), Melcret ${ }^{\circledR}$ (a dispersant), Marabond ${ }^{\circledR}$ 21 (a retarder), and Diacel ${ }^{\circledR}$ FL (a fluid-loss control additive).

The water content of the ULHS slurries is guided by the ULHS water requirement (one pound of water for each pound of ULHS). Note that the advisory board decided to use a 13.5 -lb/gal base density for the TXI Lightweight cement slurries foamed to $10.0 \mathrm{lb} / \mathrm{gal}$. Testing of the 10.0-lb/gal slurries does not include sodium-silicate slurries because the density of $10.0 \mathrm{lb} / \mathrm{gal}$ is outside of the typical working range for sodium-silicate slurries. 
There has been some concern about foaming Class A cement with a density of $15.6 \mathrm{lb} / \mathrm{gal}$ down to 11.5 and $10.0 \mathrm{lb} /$ gal, resulting in foam qualities of 26 and $36 \%$ respectively. Many experts in the industry recommend a foam quality between 25 and $35 \%$, so foaming Class A down to $11.5 \mathrm{lb} / \mathrm{gal}$ is within the recommended range and $10.0 \mathrm{lb} / \mathrm{gal}$ is not far out of that range. Although not ideal, many jobs have been successfully designed and executed using foam qualities of $36 \%$ and higher. The foamed slurries presented in this report were tested for comparison with the other lightweight slurries. As with any cement slurry that is to be pumped down a well, foamed cements should be designed, tested, and qualified for the specific application.

Table 3-Slurry Compositions for Application 2 Slurries

\begin{tabular}{|c|c|c|c|c|}
\hline \multicolumn{5}{|c|}{ Density: 10.0-lb/gal, Application 2} \\
\hline Cement Type & Slurry System & $\begin{array}{l}\text { Measured } \\
\text { Density } \\
\text { (Ib/gal) }\end{array}$ & $\begin{array}{l}\text { Water } \\
\text { Content } \\
\text { (gal/sk) }\end{array}$ & Additive Concentrations \\
\hline \multirow[b]{2}{*}{ Class A } & ULHS & 10.0 & 8.50 & $29.1 \%$ BWOC $(6 K)$ ULHS \\
\hline & Foamed & $\begin{array}{c}15.6^{\dagger} \\
\left(10.0^{\ddagger}\right)\end{array}$ & 5.19 & $\begin{array}{l}0.03 \mathrm{gal} / \mathrm{sk} \text { Witcolate }{ }^{\circledR} 7093 ; \\
0.02 \mathrm{gal} / \mathrm{sk} \text { Aromox }{ }^{\circledR} \mathrm{C} / 12\end{array}$ \\
\hline \multirow[b]{2}{*}{ TXI Lightweight } & ULHS & 10.0 & 7.23 & $\begin{array}{l}2.0 \% \text { BWOC } \mathrm{CaCl}_{2} ; \\
26.0 \% \text { BWOC (6K) ULHS }\end{array}$ \\
\hline & Foamed & $\begin{array}{c}13.5^{\dagger} \\
\left(10.0^{\ddagger}\right)\end{array}$ & 6.10 & $\begin{array}{l}2.0 \% \mathrm{BWOC} \mathrm{CaCl}_{2} ; \\
0.03 \mathrm{gal} / \mathrm{sk} \text { Witcolate }{ }^{\circledR} 7093 ; \\
0.02 \mathrm{gal} / \mathrm{sk} \text { Aromox }{ }^{\circledR} \mathrm{C} / 12\end{array}$ \\
\hline \multicolumn{5}{|c|}{ Density: 11.5-Ib/gal, Application 2} \\
\hline Cement Type & Slurry System & $\begin{array}{l}\text { Measured } \\
\text { Density } \\
\text { (lb/gal) } \\
\end{array}$ & $\begin{array}{c}\text { Water } \\
\text { Content } \\
\text { (gal/sk) }\end{array}$ & Additive Concentrations \\
\hline \multirow{3}{*}{ Class A } & ULHS & 11.5 & 7.09 & 16.2\% BWOC (6K) ULHS \\
\hline & Foamed & $\begin{array}{c}15.6^{\dagger} \\
\left(11.5^{\ddagger}\right)\end{array}$ & 5.20 & $\begin{array}{l}0.03 \mathrm{gal} / \mathrm{sk} \text { Witcolate }{ }^{\circledR} 7093 ; \\
0.02 \mathrm{gal} / \mathrm{sk} \text { Aromox }{ }^{\circledR} \mathrm{C} / 12\end{array}$ \\
\hline & Sodium Silicate & 11.5 & 16.87 & 3.0\% BWOC Sodium Silicate \\
\hline \multirow{3}{*}{ TXI Lightweight } & ULHS & 11.5 & 6.50 & $\begin{array}{l}2.0 \% \text { BWOC } \mathrm{CaCl}_{2} ; \\
11.9 \% \text { BWOC }(6 \mathrm{~K}) \text { ULHS }\end{array}$ \\
\hline & Foamed & $\begin{array}{r}13.0^{\dagger} \\
\left(11.5^{\ddagger}\right) \\
\end{array}$ & 7.00 & $\begin{array}{l}0.03 \text { gal } / \mathrm{sk} \text { Witcolate }{ }^{\circledR} 7093 ; \\
0.02 \text { gal } / \text { sk Aromox }{ }^{\circledR} \mathrm{C} / 12\end{array}$ \\
\hline & Sodium Silicate & 11.5 & 12.11 & 3.0\% BWOC Sodium Silicate \\
\hline
\end{tabular}

†Unfoamed slurry density

${ }^{\ddagger}$ Foamed slurry density 
Because of Application 2's low temperatures, calcium chloride $\left(\mathrm{CaCl}_{2}\right)$ was used with some foamed and ULHS slurries to accelerate hydration. $\mathrm{CaCl}_{2}$ was not used with the sodium silicate slurries because of viscosity issues specific to this slurry. The only viable accelerators for sodium silicate slurries are company-specific and not widely available in a generic form.

\section{Tensile Strength}

Mechanical property testing of Application 2 cement systems continued during the sixth quarter. The samples were cured at atmospheric pressure in a water bath maintained at $96^{\circ} \mathrm{F}$ (Application 2's BHST). Testing similar to that in ASTM C496-90, "Standard Test Method for Splitting Tensile Strength of Cylindrical Concrete Specimens," was performed. For this testing, specimen dimensions were 1.5 in. diameter by 1 in. long.

Figure 1 shows how each specimen is oriented on its side when tested. The force applied to the specimens was manually controlled and applied at a rate of approximately 10 $\mathrm{psi} / \mathrm{min}$.

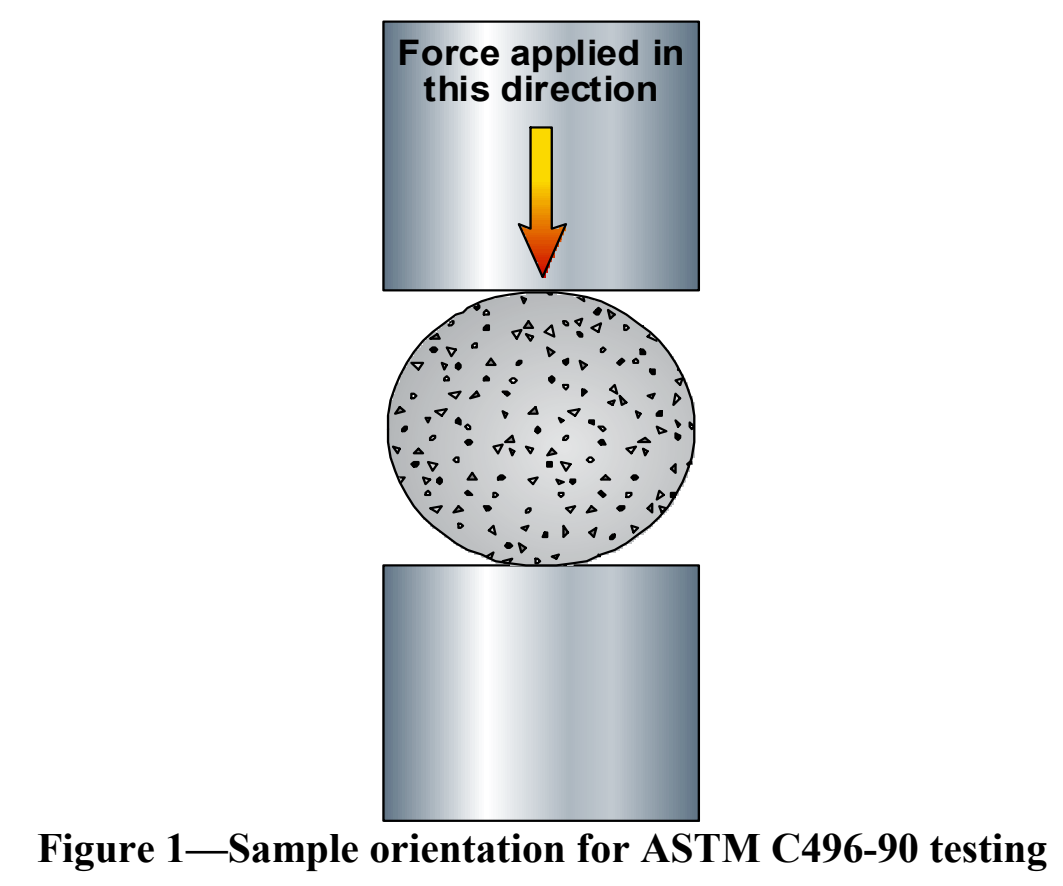

Table 4 shows the 14-day tensile strength of the slurries used in Application 2. Most data in Table 4 were gathered during the fifth quarter, but were presented again for comparison to recently gathered data. 
Table 4-Tensile Strengths of Application 2 Cements

\begin{tabular}{|c|c|c|c|c|c|}
\hline \multicolumn{6}{|c|}{ Density: 10.0 lb/gal, Application 2} \\
\hline \multirow{2}{*}{ Cement Type } & \multirow{2}{*}{ Slurry System } & \multicolumn{4}{|c|}{ Tensile Strength (psi) per ASTM C496 } \\
\hline & & Sample 1 & Sample 2 & Sample 3 & Average \\
\hline \multirow{2}{*}{ Class A } & ULHS & 241 & 241 & 304 & 262 \\
\hline & Foamed & 282 & 317 & 286 & 295 \\
\hline \multirow{2}{*}{ TX Lightweight } & ULHS & 149 & 144 & 142 & 145 \\
\hline & Foamed & 177 & 217 & 164 & 186 \\
\hline \multicolumn{6}{|c|}{ Density: 11.5 lb/gal, Application 2} \\
\hline \multirow{2}{*}{ Cement Type } & \multirow{2}{*}{ Slurry System } & \multicolumn{4}{|c|}{ Tensile Strength (psi) per ASTM C496 } \\
\hline & & Sample 1 & Sample 2 & Sample 3 & Average \\
\hline \multirow{3}{*}{ Class A } & ULHS & 236 & 214 & 286 & 245 \\
\hline & Sodium Silicate & 136 & 131 & 129 & 132 \\
\hline & Foamed & 363 & 378 & 383 & 375 \\
\hline \multirow{3}{*}{ TX Lightweight } & ULHS & 217 & 241 & 164 & 207 \\
\hline & Sodium Silicate & 199 & 212 & 210 & 207 \\
\hline & Foamed & 238 & 280 & 221 & 246 \\
\hline
\end{tabular}

To determine the effect that temperature cycling has on tensile strength, testing was conducted. The temperature cycling procedure was designed to simulate temperature conditions that might be seen during production of a well similar to the Application 2 scenario, where temperatures during production could reach $300^{\circ} \mathrm{F}$.

The samples were first cured for 14 days in a $96^{\circ} \mathrm{F}$ water bath at atmospheric pressure, then placed in a watertight container filled with water. (Figure 2) Then, the samples were subjected to five days of temperature cycling. During each of these five days, the samples were cycled as follows.

- Samples were removed from $96^{\circ} \mathrm{F}$ water bath and placed in an oven. Oven was heated to $180^{\circ} \mathrm{F}$ in four minutes. Samples remained in $180^{\circ} \mathrm{F}$ oven for one hour.

- Oven was heated to $300^{\circ} \mathrm{F}$ in five minutes. Samples remained in $300^{\circ} \mathrm{F}$ oven for four hours.

- Oven was cooled to $180^{\circ} \mathrm{F}$ in 15 minutes. Samples remained in $180^{\circ} \mathrm{F}$ oven for one hour.

- Oven was cooled to $96^{\circ} \mathrm{F}$ in 15 minutes. Samples were placed back in $96^{\circ} \mathrm{F}$ water bath.

The samples were placed in the watertight containers to keep water on the cement samples and prevent the water from boiling off. 


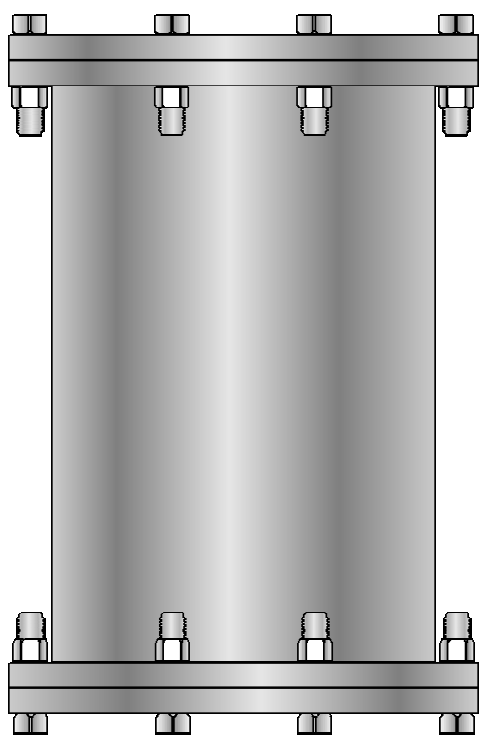

Figure 2-Watertight container for temperature cycling

Table 5 presents the tensile strengths of the three cement systems that were exposed to five temperature cycles. Note that the cements did not contain silica to combat strength retrogression. For comparison, Table 5 also shows tensile strength data that was in the fifth quarterly report. This additional tensile strength data is from samples that were not temperature cycled, but they were cured for 14 days at atmospheric pressure in a water bath maintained at $96^{\circ} \mathrm{F}$.

Table 5-Tensile Strength Data of Lightweight Cements

\begin{tabular}{|c|c|c|c|c|c|c|}
\hline \multicolumn{7}{|c|}{ Density: 11.5 lb/gal, Application 2} \\
\hline \multirow{3}{*}{ Cement Type } & \multirow{3}{*}{ Slurry System } & \multicolumn{5}{|c|}{ Tensile Strength (psi) per ASTM C496 } \\
\hline & & \multicolumn{4}{|c|}{ Temperature Cycled } & \multirow{2}{*}{$\frac{\text { Not Temperature Cycled }}{\text { Average }}$} \\
\hline & & Sample 1 & Sample 2 & Sample 3 & Average & \\
\hline \multirow{3}{*}{ Class A } & ULHS & 136 & 136 & 129 & 134 & 245 \\
\hline & Sodium Silicate & 52 & 57 & 57 & 55 & 132 \\
\hline & Foamed & 125 & 125 & 118 & 123 & 375 \\
\hline
\end{tabular}

Depending on the decisions of the advisory board, future temperature-cycled tensile strength tests may also be run on the TXI Lightweight cement slurries and on cement slurries with silica to diminish the potential effects that strength retrogression might have on the tensile strength.

\section{Compressive Strength}

Compressive strength testing was also done on cement samples that had been temperature cycled. The samples had a 1.5-in. diameter and an average length of $2.75 \mathrm{in}$. to better accommodate the container (Figure 2) used for temperature cycling. 
The samples were cured for 14 days at atmospheric pressure in a $96^{\circ} \mathrm{F}$ water bath. The samples were then placed in the watertight container filled with water. Then, the samples were subjected to five days of temperature cycling. During each of these five days of temperature cycling, the cured samples were cycled as follows.

- Samples were removed from $96^{\circ} \mathrm{F}$ water bath and placed in an oven. Oven was heated to $180^{\circ} \mathrm{F}$ in 4 minutes. Samples remained in $180^{\circ} \mathrm{F}$ oven for 1 hour.

- Oven was heated to $300^{\circ} \mathrm{F}$ in 5 minutes. Samples remained in $300^{\circ} \mathrm{F}$ oven for 4 hours.

- Oven was cooled to $180^{\circ} \mathrm{F}$ in 15 minutes. Samples remained in $180^{\circ} \mathrm{F}$ oven for 1 hour.

- Oven was cooled to $96^{\circ} \mathrm{F}$ in 15 minutes. Samples were placed back in $96^{\circ} \mathrm{F}$ water bath.

The samples were then placed vertically in a press and crushed to determine compressive strength. The results of these tests can be seen in Table 6. For broad comparison, compressive strengths are also presented of 2-in. cube samples that were cured for 7 days at atmospheric pressure in a $96^{\circ} \mathrm{F}$ water bath and were not temperature cycled.

Table 6-Compressive Strengths of Lightweight Cements

\begin{tabular}{|c|c|c|c|c|c|c|}
\hline \multicolumn{7}{|c|}{ Density: 11.5 lb/gal, Application 2} \\
\hline \multirow{4}{*}{$\begin{array}{c}\text { Cement } \\
\text { Type }\end{array}$} & \multirow{4}{*}{ Slurry System } & \multicolumn{5}{|c|}{ Compressive Strength (psi) } \\
\hline & & \multicolumn{4}{|c|}{ Temperature Cycled } & Not Temperature Cycled \\
\hline & & \multicolumn{4}{|c|}{14 days, cylinder } & 7 days, 2 -in cube \\
\hline & & Sample 1 & Sample 2 & Sample 3 & Average & Average \\
\hline \multirow{3}{*}{ Class A } & ULHS & 3038 & 2994 & 3891 & 3308 & 2140 \\
\hline & Sodium Silicate & 306 & 393 & - & 350 & 350 \\
\hline & Foamed & 2540 & 2435 & 1902 & 2292 & 1180 \\
\hline
\end{tabular}

Depending on the decisions of the advisory board, future temperature-cycled compressive-strength tests may also be run on the TXI Lightweight cement slurries and on cement slurries with silica.

\section{Young's Modulus}

In the fifth project quarter, data for the mechanical properties of different cement systems were presented. Young's modulus and effective compressive-strength data were presented for the Application 2 cements. The difference between the failure strength and the confining pressure is the effective compressive strength. In a continuation of the study of the mechanical properties, testing during this quarter was conducted on neat 15.6lb/gal Class A cement and on TXI Lightweight cement at $13.5 \mathrm{lb} / \mathrm{gal}$. The Young's modulus data of the neat Class A and TXI Lightweight cements can be used as another way to compare the performance of the ULHS, sodium silicate, and foamed cements.

The Young's modulus samples of the neat Class A and neat TXI Lightweight cements were cured for 14 days at atmospheric pressure in a $96^{\circ} \mathrm{F}$ water bath. The samples were molded in a cylinder and cut to length and not cored. 
"ASTM C469, Standard Test Method for Static Modulus of Elasticity (Young's Modulus) and Poisson's Ratio of Concrete in Compression," was followed for the Young's modulus testing. The diameter of each test specimen was 1.5 in, and the length was 3.0 in.

The following procedure was used for the Young's modulus testing.

1) Each sample was inspected for cracks and defects.

2) The sample was cut to a length of $3.0 \mathrm{in}$.

3) The sample's end surfaces were ground to obtain a flat, polished surface with perpendicular ends.

4) The sample's physical dimensions (length, diameter, weight) were measured.

5) The sample was placed in a Viton jacket.

6) The sample was mounted in the Young's modulus testing apparatus.

7) The sample was brought to 100-psi confining pressure and axial pressure. The sample was allowed to stand for 15-30 min until stress and strain were at equilibrium. (In unconfined testing, only axial load was applied.)

8) Axial and confining stresses were increased at a rate of $25-50 \mathrm{psi} / \mathrm{min}$ to bring the sample to the desired confining stress condition. The sample was allowed to stand until stress and strain were at equilibrium.

9) The sample was subjected to a constant strain rate of $0.0019 \mathrm{in} . / \mathrm{min}(0.05 \mathrm{~mm} / \mathrm{min})$.

10) During the test, the pore lines on the end cups of the piston were opened to atmosphere to avoid any pore-pressure buildup.

11) After the sample failed, the system was returned to the atmospheric stress condition and the sample was removed from the cell.

Table 7 presents the Young's modulus data of the neat Class A and neat TXI Lightweight cements. Table 8 presents Young's modulus data that were gathered prior to the sixth quarter. Table 8 shows Young's modulus data of the 11.5-lb/gal lightweight cement systems for Application 2. These samples were also cured for 14 days at atmospheric pressure in a $96^{\circ} \mathrm{F}$ water bath.

Table 7-Young's Modulus Data of Neat Class A and TXI Lightweight Cements

\begin{tabular}{|c|c|c|c|c|}
\hline \multirow[t]{2}{*}{ Cement Type } & \multicolumn{2}{|c|}{$\begin{array}{l}\text { Young's Modulus }\left(10^{5} \mathrm{psi}\right) \\
\text { at Confining Pressure (psi) }\end{array}$} & \multicolumn{2}{|c|}{$\begin{array}{c}\text { Effective Compressive Strength (psi) } \\
\text { at Confining Pressure (psi) }\end{array}$} \\
\hline & 0 & 1,000 & 0 & 1,000 \\
\hline Class A & 11.6 & 11.2 & 5,820 & 7,700 \\
\hline TXI Lightweight & 9.30 & 9.01 & 4,740 & 5,000 \\
\hline
\end{tabular}


Table 8-Young's Modulus Data of 11.5-lb/gal Lightweight Cements

\begin{tabular}{|c|c|c|c|c|c|}
\hline \multirow[t]{2}{*}{ Cement Type } & \multirow[t]{2}{*}{ Slurry System } & \multicolumn{2}{|c|}{\begin{tabular}{|c|}
$\begin{array}{c}\text { Young's Modulus }\left(10^{5} \mathrm{psi}\right) \text { at } \\
\text { Confining Pressure (psi) }\end{array}$ \\
\end{tabular}} & \multicolumn{2}{|c|}{$\begin{array}{l}\text { Effective Compressive Strength } \\
\text { (psi) at Confining Pressure (psi) }\end{array}$} \\
\hline & & 0 & 1,000 & 0 & 1,000 \\
\hline \multirow{3}{*}{ Class A } & ULHS & 4.24 & 3.37 & 3,880 & 4,773 \\
\hline & Sodium Silicate & 0.59 & 0.22 & 315 & 777 \\
\hline & Foamed & 2.50 & 1.21 & 1,590 & 2,041 \\
\hline \multirow{3}{*}{ TXI Lightweight } & ULHS & 3.71 & 2.21 & 3,300 & 6,372 \\
\hline & Sodium Silicate & 1.99 & 0.45 & 965 & 1,078 \\
\hline & Foamed & 2.70 & 1.75 & 2,420 & 2,910 \\
\hline
\end{tabular}

\section{Shear Bond}

Testing continued with the evaluation of the shear bond strength of the three cement systems. These studies investigated the effect of restraining force on shear bond strength. Samples were cured in a pipe-in-pipe configuration (Figure 3) and in a pipe-in-soft configuration (Figure 4). The pipe-in-pipe configuration consisted of a sandblasted internal pipe with an outer diameter (OD) of $1 \frac{1}{16}$ in. and a sandblasted external pipe with an internal diameter (ID) of 3 in. Both pipes were 6 in. long. To center the internal pipe within the external pipe, a contoured base and top were used. The base extended 1 in. into the annulus and cement filled 4 in. of the annulus. The top $1 \mathrm{in}$. of annulus contained water.

To allow the cement to cure in a less-rigid, lower-restraint environment, plastisol was used for the pipe-in-soft shear bond strength tests. Plastisol, a mixture of a resin and a plasticizer, creates a soft, flexible substance. The plastisol blend used for these tests (PolyOne's Denflex PX-10510-A) creates a substance with a 40-duro hardness.

The pipe-in-soft configuration contained a sandblasted external pipe with an ID of 4 in. A molded plastisol sleeve (with an ID of 3.0 in. and uniform thickness of 0.5 in.) fit inside this external pipe. Using a contoured base and top, a sandblasted internal pipe with an OD of $1 \frac{1}{16}$ in. was centered within the plastisol sleeve. The pipes and sleeve were 6 in. long. The base extended $1 \mathrm{in}$. into the annulus and cement filled the annulus to a length of 4 in. between the plastisol sleeve and the inner $1 \frac{1}{16}$-in. pipe. The top inch of annulus was filled with water. 


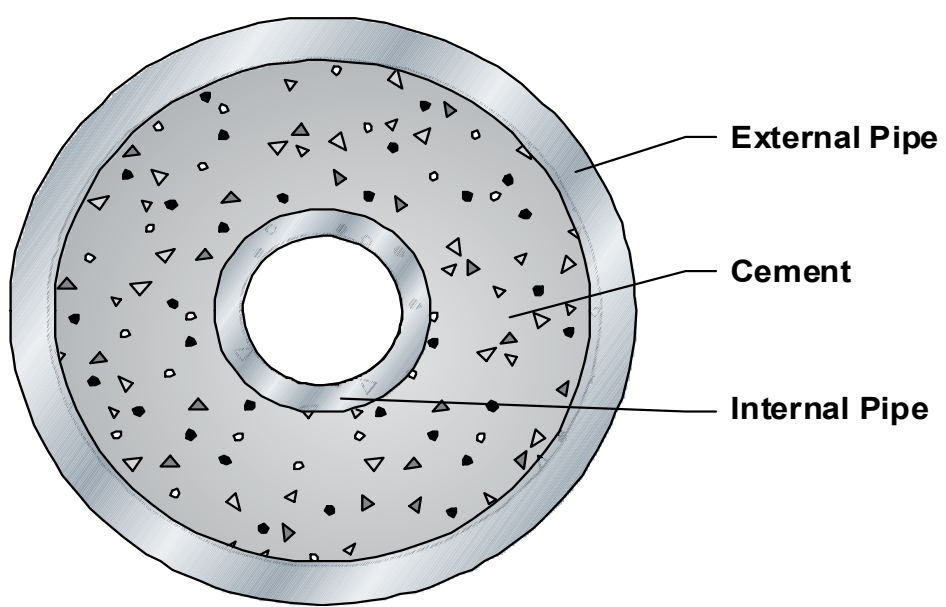

Figure 3-Cross section of pipe-in-pipe configuration for shear bond tests

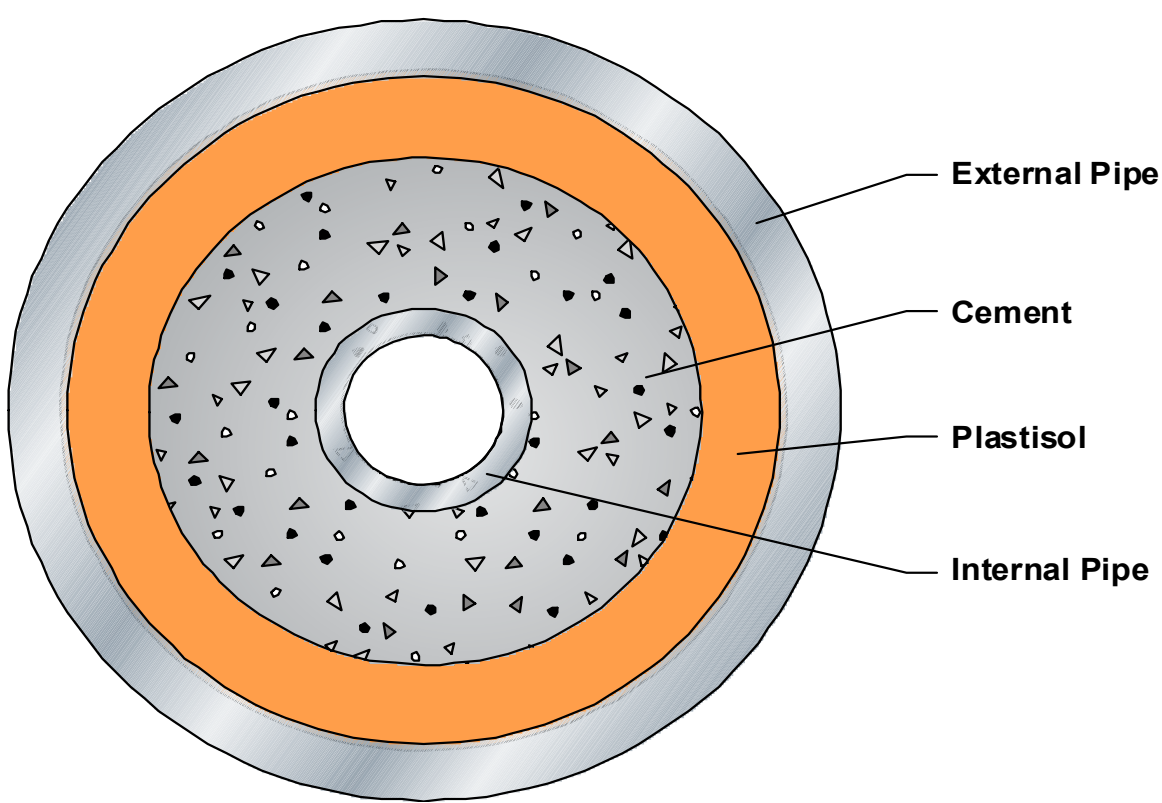

Figure 4-Cross section of pipe-in-soft configuration for shear bond tests

Application 2 cement systems were used for the shear bond strength tests. Testing to determine the effect of temperature cycling on shear bond strength was conducted. The temperature cycling procedure was designed to simulate temperature conditions encountered during production of a well similar to the Application 2 scenario, in which production temperatures could reach $300^{\circ} \mathrm{F}$.

The samples were first cured for seven days in a $96^{\circ} \mathrm{F}$ water bath at atmospheric pressure. They were then subjected to five days of temperature cycling. During each day of temperature cycling, the cured samples were cycled as follows.

- Samples were removed from $96^{\circ} \mathrm{F}$ water bath and placed in an oven. Oven was heated to $180^{\circ} \mathrm{F}$ in 4 minutes. Samples remained in $180^{\circ} \mathrm{F}$ oven for 1 hour.

- Oven was heated to $300^{\circ} \mathrm{F}$ in 5 minutes. Samples remained in $300^{\circ} \mathrm{F}$ oven for 4 hours. 
- Oven was cooled to $180^{\circ} \mathrm{F}$ in 15 minutes. Samples remained in $180^{\circ} \mathrm{F}$ oven for 1 hour. - Oven was cooled to $96^{\circ} \mathrm{F}$ in 15 minutes. Samples were placed back in $96^{\circ} \mathrm{F}$ water bath.

Because of the high temperatures associated with the temperature cycling, these shear bond samples were cured using a special configuration with a flange on the outside of the external pipe and at both ends. Each flange had holes that allow a flat, watertight lid to be bolted to it (Figure 2). The watertight lids kept water on the cement and prevented the water from boiling off. The lids were placed on the samples at the end of the seven days of curing at $96^{\circ} \mathrm{F}$.

Shear bond measures the stress needed to break the bond between the cement and the internal pipe. Shear bond was measured with the aid of a test jig that creates a platform for the base of the cement to rest against as force is applied to the internal pipe. (Figure 5) Shear bond force is the force required to move the internal pipe. The pipe was pressed until the bond was broken; the pipe was not pushed out of the cement. The shear bond strength is the force required to break the bond (move the pipe) divided by the surface area between the internal pipe and the cement.

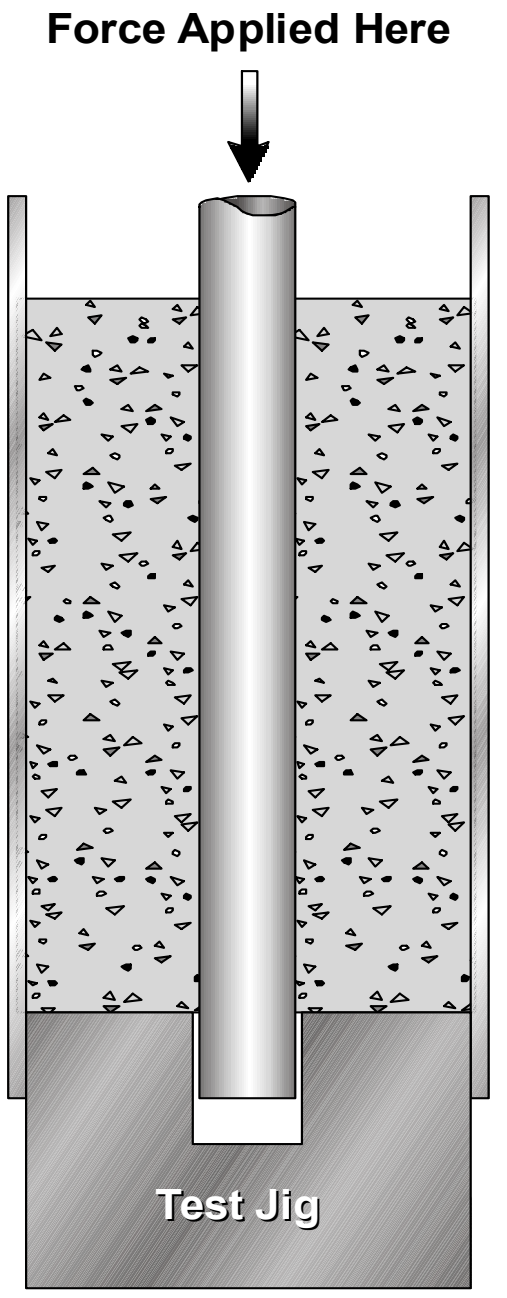

Figure 5-Configuration for testing shear bond strength 
Table 9 presents the seven-day shear bond strengths for the three cement systems in the pipe-in-pipe and pipe-in-soft configurations. The results of the temperature-cycled pipein-pipe shear bonds are also presented in Table 9. Note that the cements did not contain silica to combat strength retrogression.

The shear bond strengths of the TXI Lightweight cements in the pipe-in-soft configuration were low. To get a better understanding of what could be causing the low shear bond strength, expansion testing is being conducted and will be reported in the next quarterly report. Shear bond tests may be done on temperature-cycled TXI Lightweight cements after analyzing the outcome of the expansion testing. 


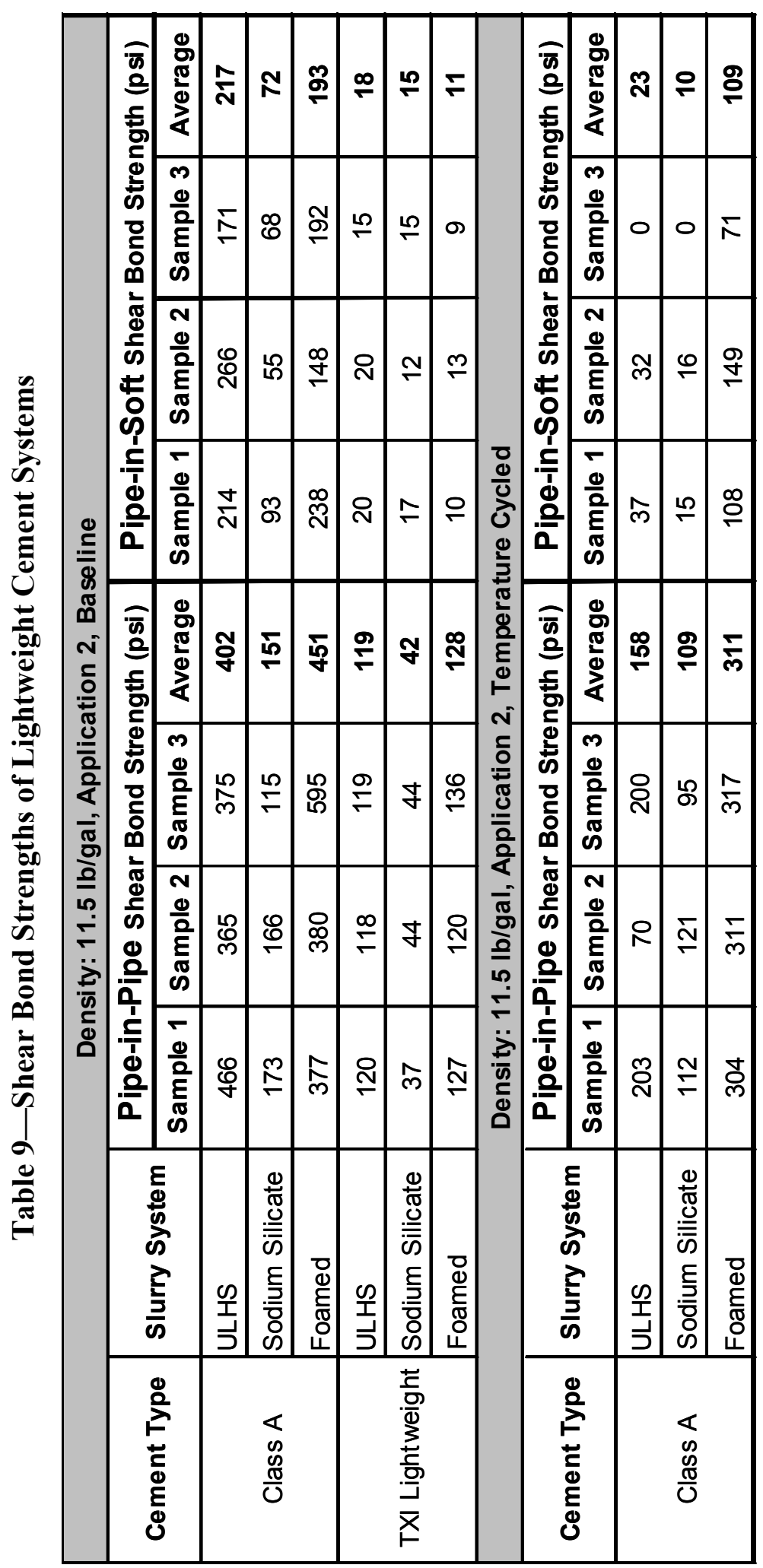




\section{Software Program}

A software program is being created to assist in designing foamed cements and cement slurries made with ULHS. The program does not simulate cement jobs and fluid dynamics. Instead, the program focuses on the static final placement of the fluids. To date, the work that has been done related only to ULHS cement slurries. Screen captures of the current program and their description follow.

The first window that the user of the program encounters is Cement Slurry window with the Well and Other Data tab active (see Figure 6). To help the user understand the program and the required data, a fixed graphic of a wellbore also appears on the Well and Other Data tab. "Fixed" means that the graphic does not change when the user inputs data. The program accepts a wellbore geometry with input for one previously-cemented casing and an open hole with one geometry (diameter and excess annular volume). To make the program easier to use, fluid input is available for one mud, one spacer, one lead cement, and one tail cement. If more than one fluid will be used for each case, the data for the multiple fluids must be consolidated and entered as one fluid. For example, a preflush and a spacer should be consolidated by using the sum of the lengths (or volumes) and a weighted average of their densities. When inputting volumes for the tail cement, the software program considers only the tail cement in the annulus and not the cement in the shoe joint.

To use the program, the user would first select a slurry type from the Cement Slurry Type box. In the current version of the program, the options read as Cement Slurry and Foam Cement Slurry (not yet activated). To better distinguish the ULHS cement slurry option, in the next version, the options will read as ULHS Cement Slurry and Foam Cement Slurry. To date, the work that has been done is for ULHS cement slurries; the windows for the foamed cements have not been created yet and will not be presented in this report.

In addition to the Cement Slurry Type box, the Well and Other Data tab has a box with the eleven required fields and a set of toggle buttons that allow the user to select the way in which the fluid information will be entered. The options are By Length and By Volume. Figure 6 shows the required fields when By Length is selected-Length of Spacer, Length of Lead Cement, and Length of Tail Cement. The unit for those fields is $f t$. When By Volume is selected, the fields are Volume of Spacer, Volume of Lead Cement, and Volume of Tail Cement, and the unit for those fields is $b b l$. Other required fields address wellbore geometry and mud and spacer densities.

In the next software version, the Well and Other Data window will be changed to read Current Casing OD, rather than Drill Pipe OD. Additionally, the Excess Volume field will be renamed Excess Annular Volume. A revision that will be made throughout the program will be to change the term "foam" to "foamed." 


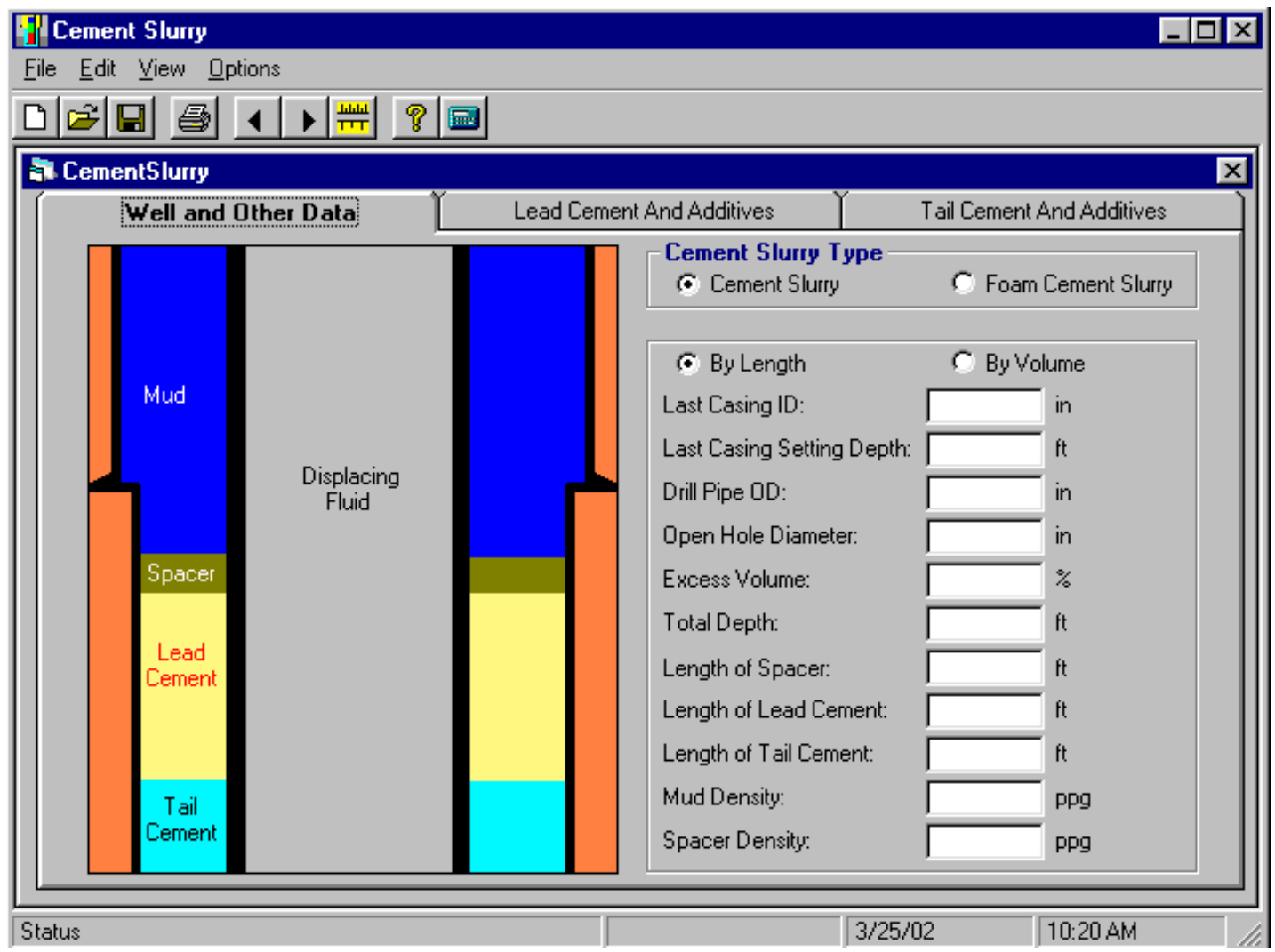

Figure 6-Well and Other Data tab

The next tab is the Lead Cement and Additives tab (see Figure 7). Slurry information for the lead cement is entered on this tab. The Lead Cement and the Tail Cement tabs are organized the same way. In the next version of the software, the term "beads" on the Tail Cement and the Lead Cement tabs will be changed to "ULHS."

The yellow fields circled in Figure 7 are information-only fields that change when data that is entered into fields on this tab and on the Well and Other Data tab. Another revision for the software will be for the Pressure at Middle of Lead Cement field. This field was incorrectly designed to present the hydrostatic pressure to be used for calculating the extent of ULHS crushing and the resulting crushed ULHS specific gravity. The next version of the software will calculate the range of hydrostatic pressures that the cement will experience as it first enters the annulus and as the last part of the cement enters the annulus. These conditions will bracket the possibilities of highest hydrostatic pressures. (At this time, friction pressure is not factored into the pressure calculations.) An average of the two hydrostatic pressures will be used in determining the amount of crushing done to the ULHS. The resulting crushed specific gravity will be displayed in the Beads [ULHS] Specific Gravity field. The field title, Pressure at Middle of Lead Cement, will be either renamed to reflect these corrections or the field and its title will not be displayed. The same revisions will be made on the Tail Cement and Additives tab. 


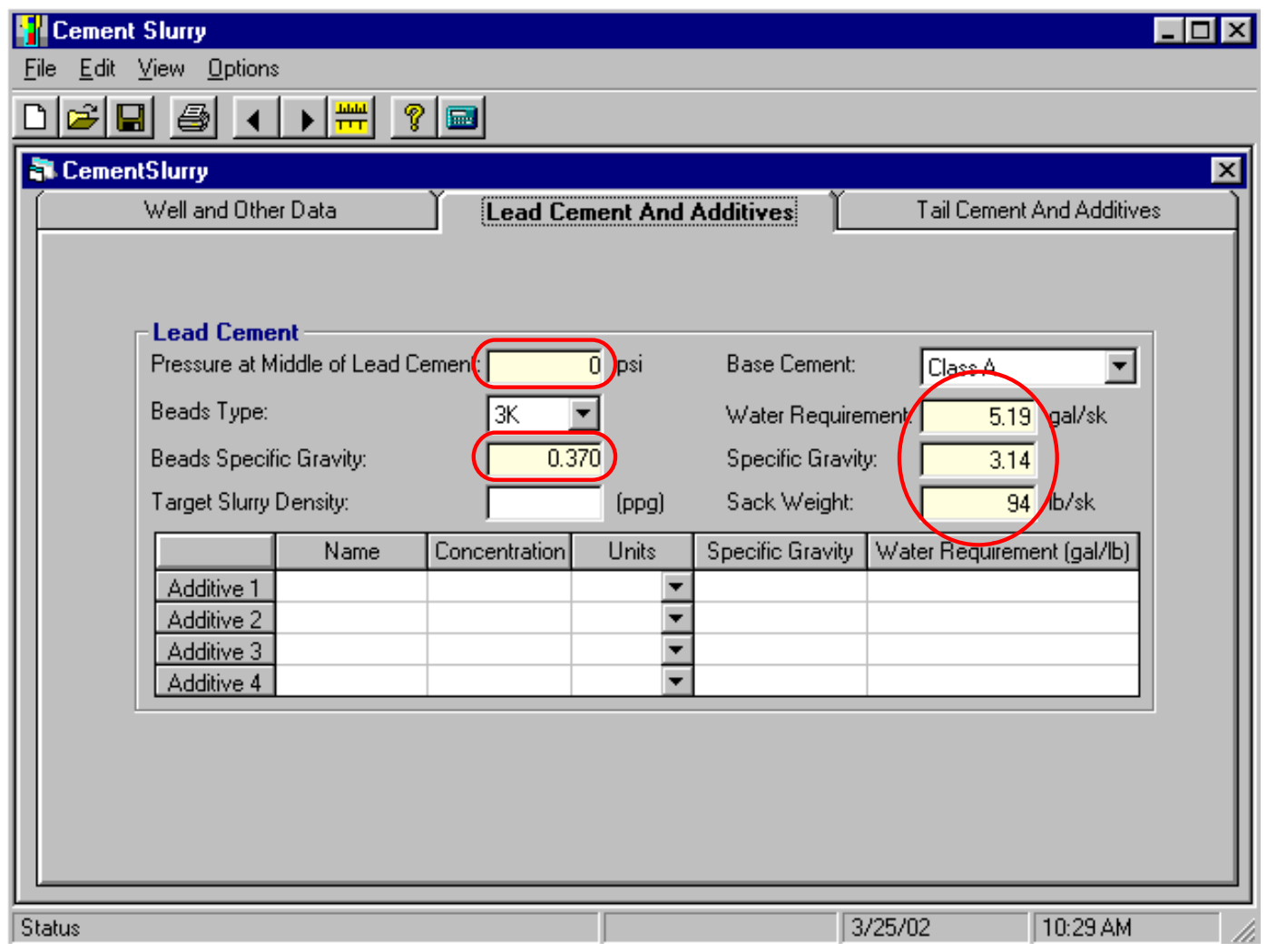

Figure 7-Lead Cement and Additives tab

Figure 8 shows the dropdown menu for the Beads [ULHS] Type field. The type of ULHS that is chosen will determine the specific gravity at surface and at the hydrostatic pressure experienced by the ULHS during the cement job. The resulting (crushed) downhole specific gravity is displayed in the ULHS Specific Gravity field. The "crushed" specific gravity database used for this program comes from laboratory tests previously performed in this project. 


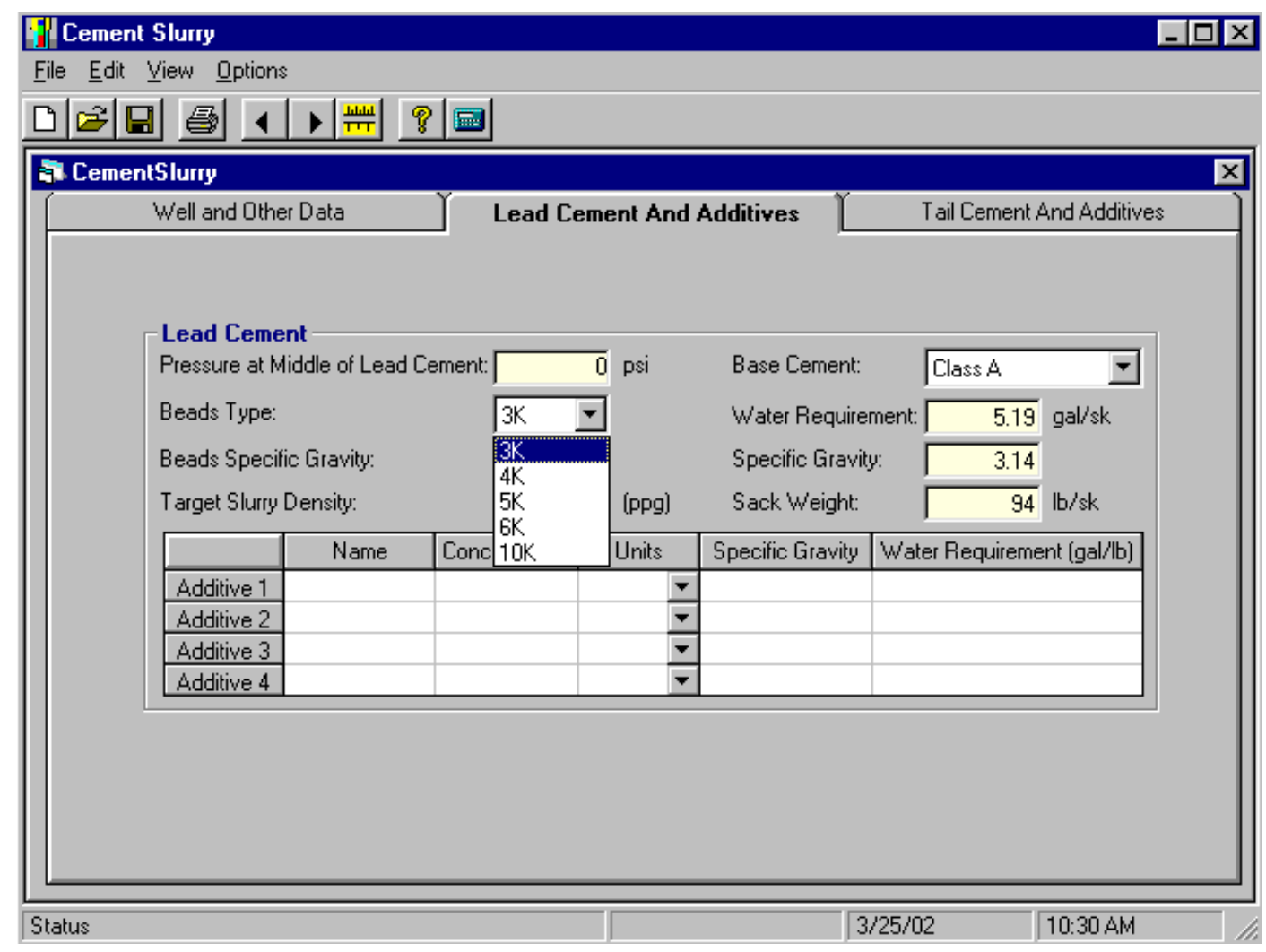

Figure 8-Drop-down menu for ULHS Type field

On the right side of the Lead Cement tab, information about the cement is entered and displayed. A dropdown menu in the Base Cement field allows the user to select the type of cement. (Figure 9) Once the cement is selected, the related yellow information-only fields (Water Requirement, Specific Gravity, and Sack Weight) are automatically populated from a database for the specific cement chosen. One of the dropdown menu options in the Base Cement field is Other Cement. When Other Cement is selected, the user can enter data for the Water Requirement, Specific Gravity, and Sack Weight. 


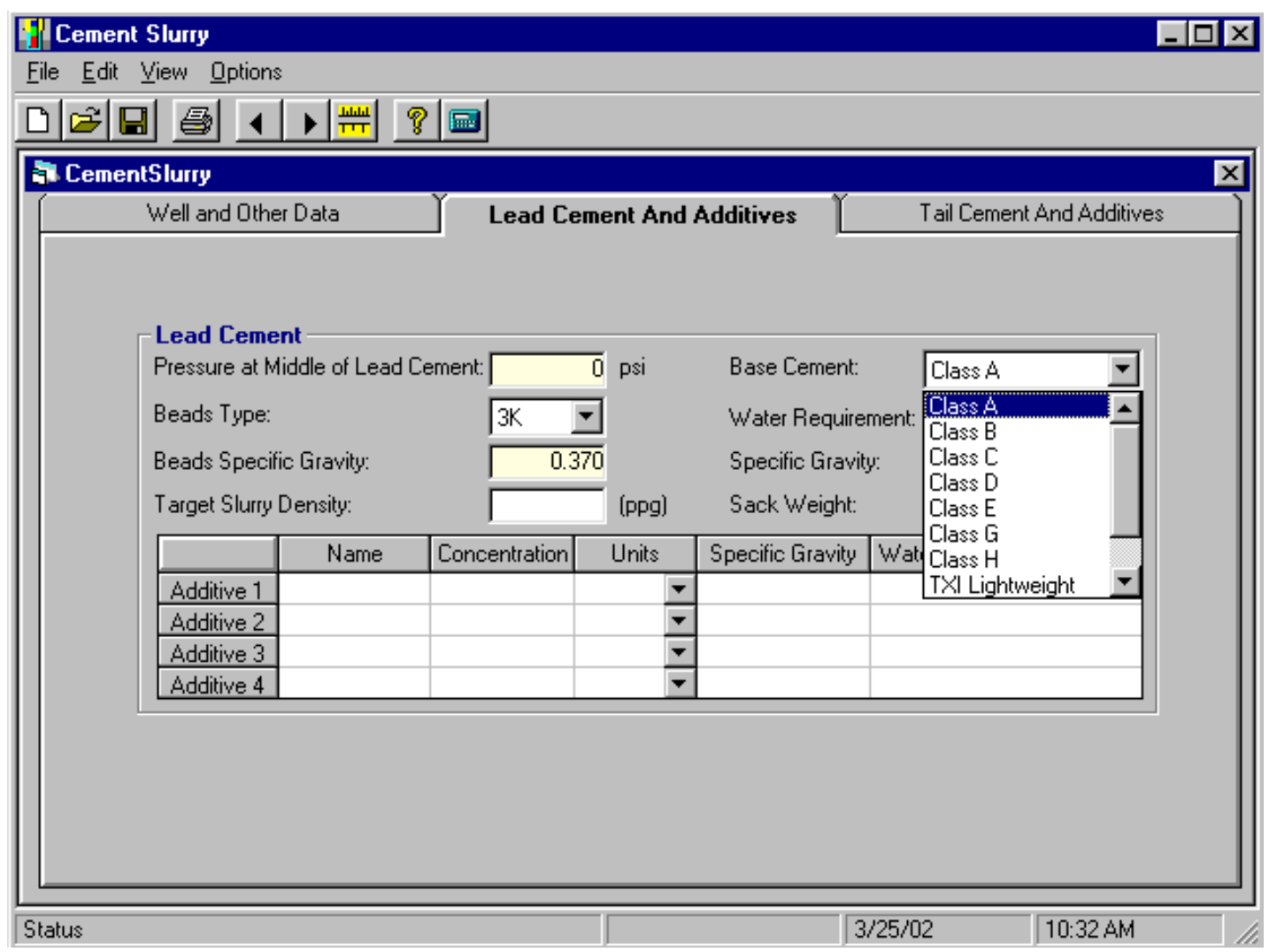

Figure 9-Drop-down menu for Base Cement field

The lower portion of the Lead Cement tab is used to enter information about other additives in the lead cement slurry. As shown in Figure 10, the Units field has a dropdown menu with three options - lb/sk, gal/sk, and \%BWOC. For the next software version, \% BWOW will be added as another option in the Units field. 


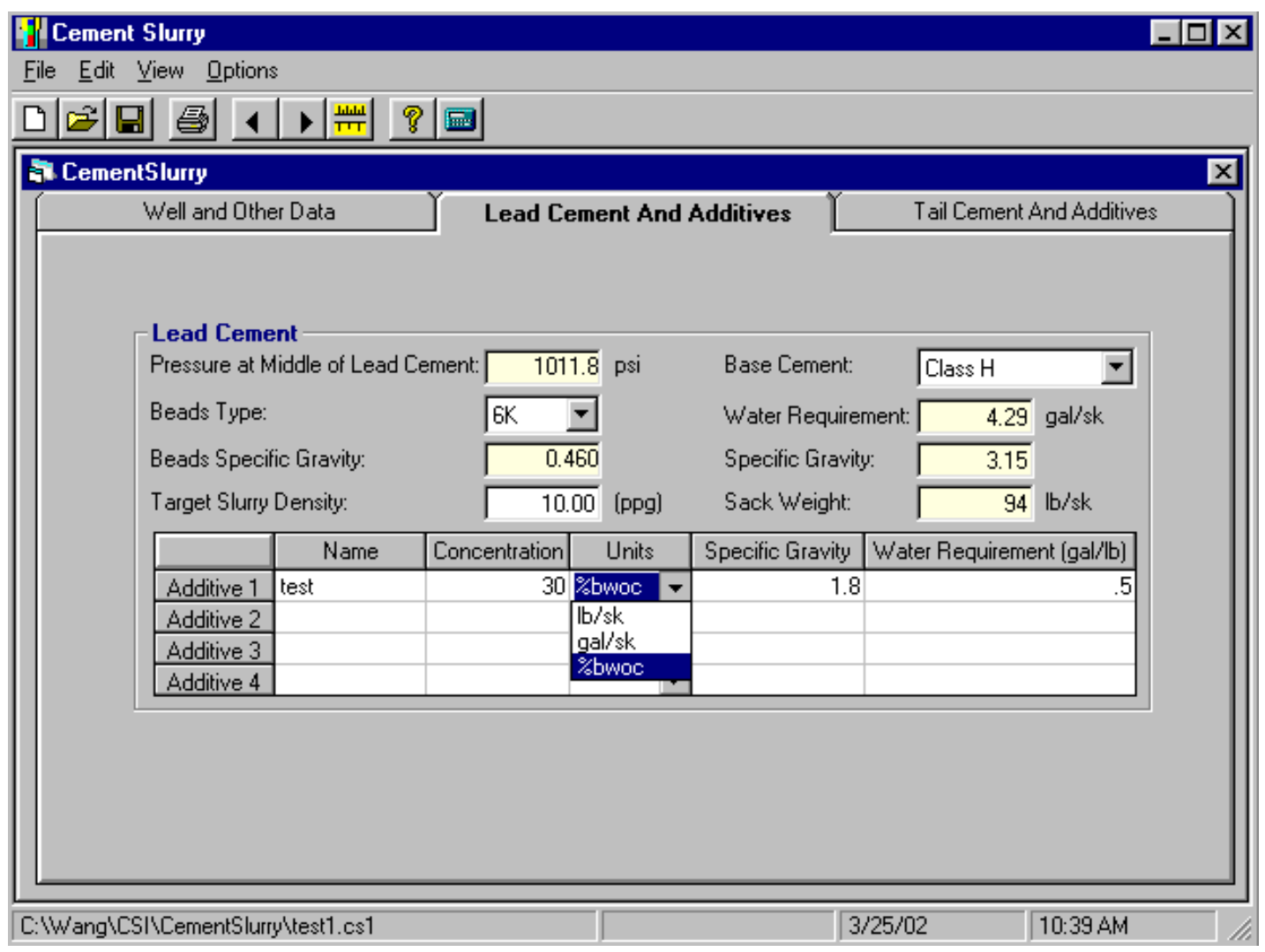

Figure 10-Drop-down menu for Units field

Once all the data is correctly entered into the input tabs (Well and Other Data, Lead Cement and Additives, and Tail Cement and Additives), the user can click the output button (located on the toolbar) to view the Output window (Figure 11). The program is designed to calculate the ULHS concentration, slurry water requirement, and the cement slurry yields. The water requirement is calculated using the water requirements of the cement, additives, and the ULHS. Using an algorithm, the program varies the ULHS concentration (thereby varying the water requirement) to attain the desired slurry density. The input button 1 on the toolbar can be used to toggle back to the input tabs, from which the input data can be reviewed or changed.

The last item in the Output window is a third ULHS Concentration field that has units in $\mathrm{ft}$. This field is intended to be Length of Mud and will be changed to read as such in the next version. 


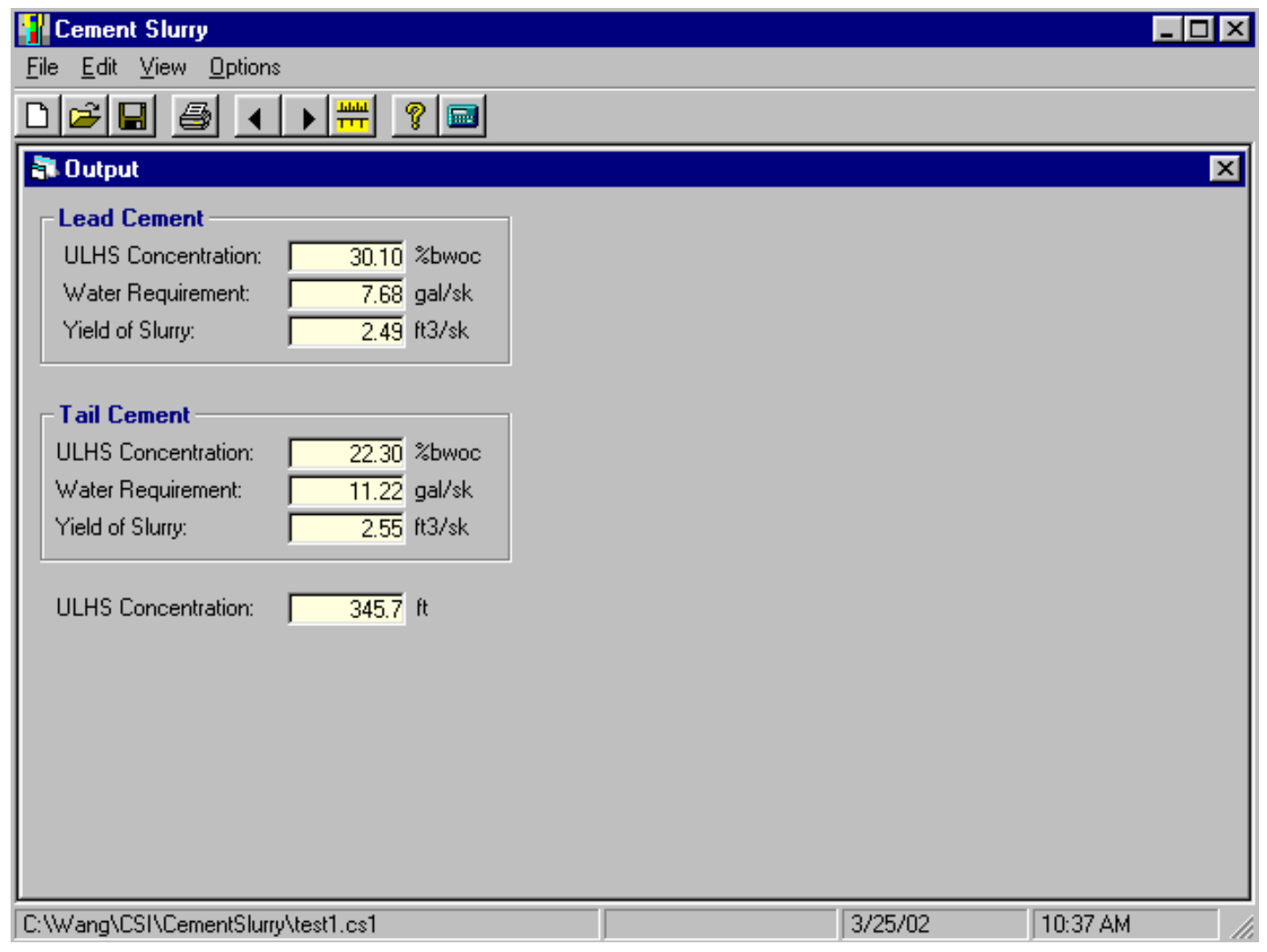

Figure 11-Output window

\section{Plans for Seventh Project Quarter}

The following investigations and tests are planned for the next project quarter.

- Further experiments on the alkali-reactivity of ULHS will be conducted.

- To determine the competence of ULHS and other lightweight cement systems during drillout, testing will be conducted. The tests will measure bulk permeability of the cement before and after drillout.

- To get a better understanding of what could be causing the low shear bond strength of the TXI Lightweight cement systems, expansion testing will be conducted.

- Another field job using ULHS is planned for the seventh quarter. The job planned for the end of the first week of April was cancelled because of a dry hole.

- Work will continue on the software program that will assist with ULHS and foamed cement slurry design. 
- Tests will be performed on ULHS, sodium silicate, and foamed cements to evaluate the effect of pressure testing on shear bond strength.

\section{Conclusions}

Results from temperature-cycling tests have been presented. Tests will be done to determine if deterioration of strength due to temperature cycling can be prevented by the use of silica.

Tests will be done to complete the suite of tests on temperature cycling. 


\section{List of Acronyms and Abbreviations}

API-American Petroleum Institute

ASR - alkali-silica reactivity

ASTM-American Society for Testing and Materials

$\mathrm{Bc}$-Bearden units of consistency

BHCT - bottomhole circulating temperature

BHST - bottomhole static temperature

BWOC - by weight of cement

BWOW - by weight of water

$\mathrm{CaCl}_{2}$ - chemical formula for calcium chloride

cp-centipoise

gal-gallon

$\mathrm{H}_{2} \mathrm{O}$ - chemical formula for water

ID_-inner diameter

in. - inch

J-Joule

$\mathrm{lb}$ - pound

md-millidarcy

min-minute

OD_outer diameter

psi-pound per square inch

rev-revolution

$\mathrm{s}$ - second

sk-sack of cement

QC-quality control

TXI-Texas Industries

TXI LW - manufactured lightweight cement available from TXI

ULHS - ultra-lightweight hollow (glass) spheres

$3 \mathrm{~K}-3,000$-psi designation

$6 \mathrm{~K}-6,000-\mathrm{psi}$ designation 


\section{References}

1. API Specification 10A: "Specifications for Cements and Materials for Well Cementing," 22nd Edition, American Petroleum Institute, Washington, D.C., January 1995.

2. Worldwide Cementing Practices, First Edition, American Petroleum Institute, January 1991.

3. API Recommended Practice 10B: "Recommended Practice for Testing Well Cements," 22nd Edition, American Petroleum Institute, Washington, D.C., December 1997. 


\section{Appendix A-Quality Control Testing}

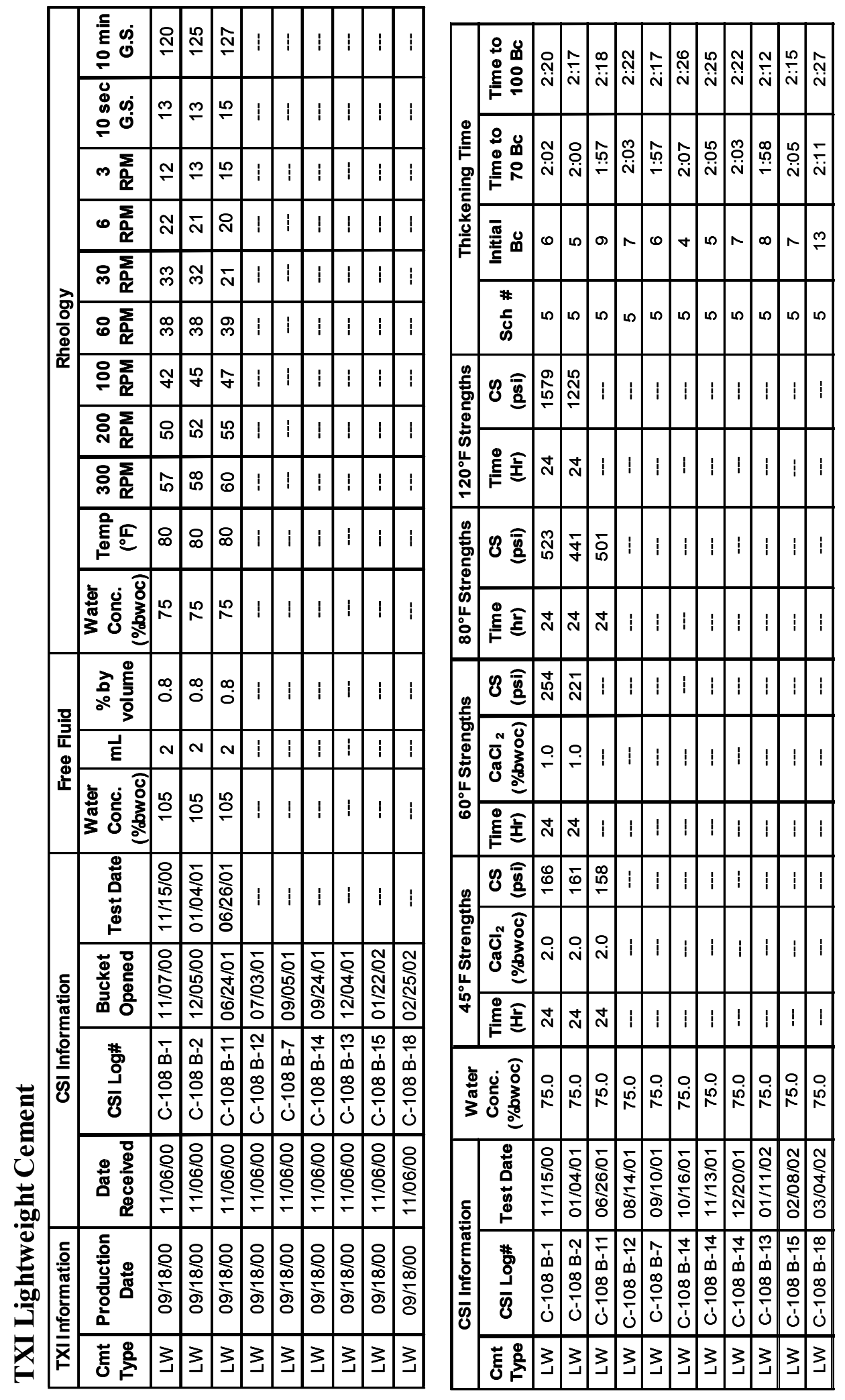



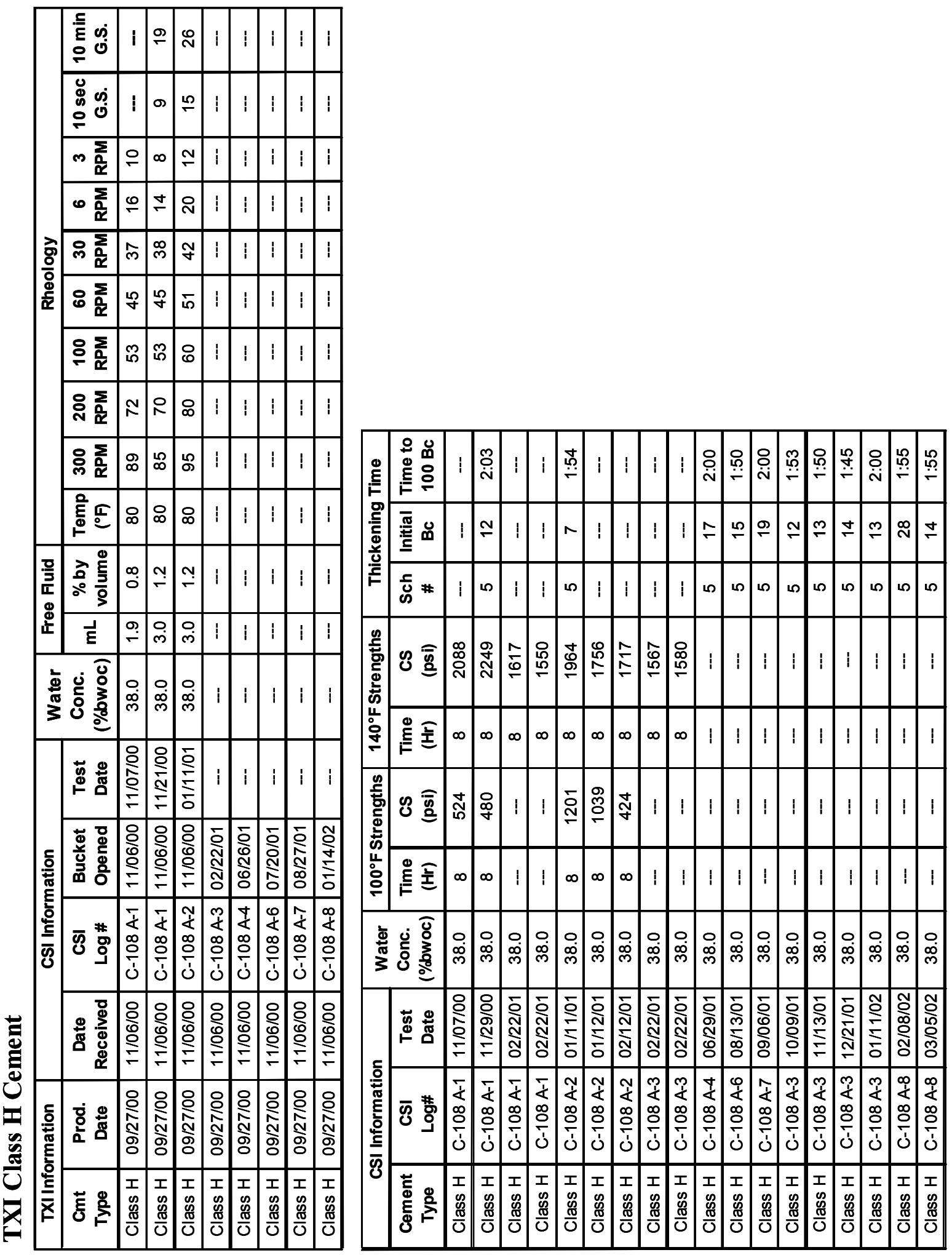


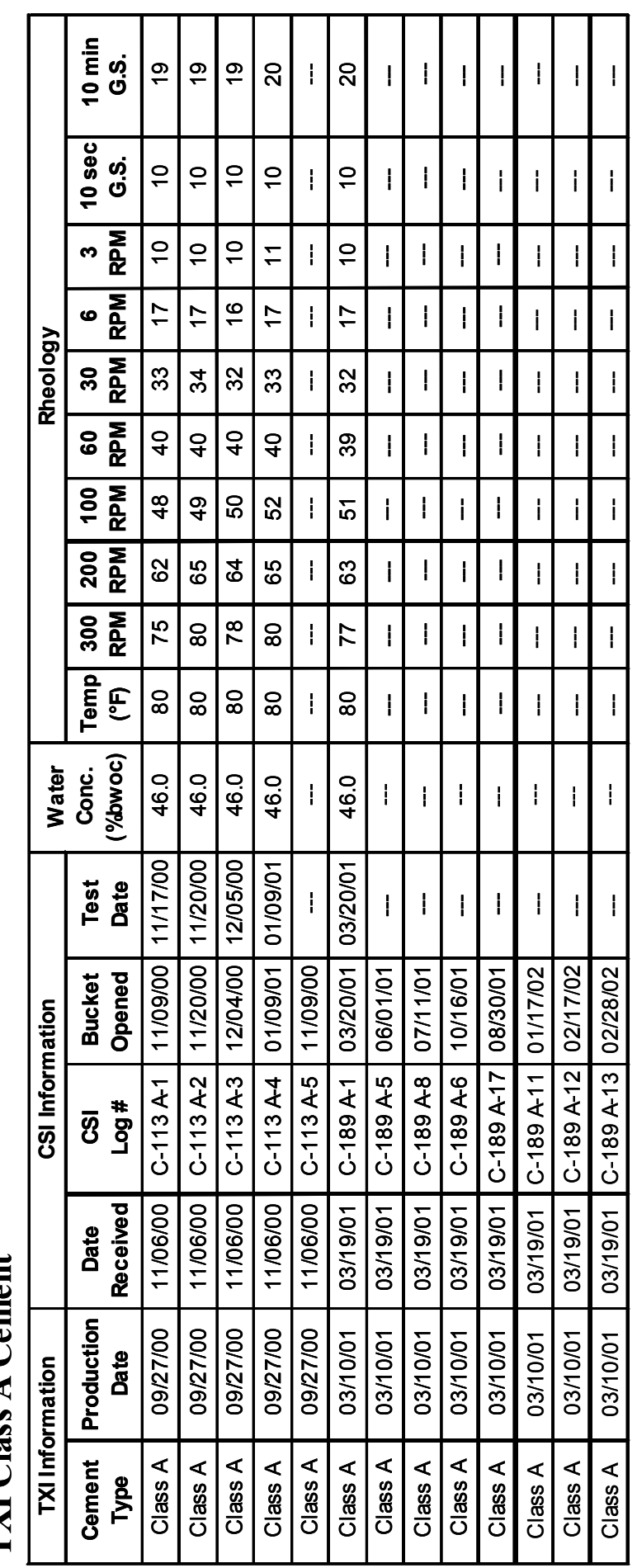

\begin{tabular}{|c|c|c|c|c|c|c|c|c|c|c|c|c|c|c|c|c|c|c|c|c|}
\hline \multirow[b]{4}{*}{$=$} & 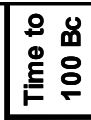 & $\overline{\grave{i}}$ & ָָ̀ & 1 & ; & $\mid \begin{array}{l}\stackrel{g}{\mathrm{i}} \\
\mathbf{N}\end{array}$ & 1 & 1 & 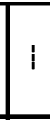 & 1 & 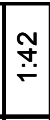 & $\mid \widehat{m}$ & |م & 吕 & 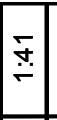 & ?ִּ & $\stackrel{0}{\stackrel{0}{+}}$ & 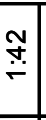 & 吕 & 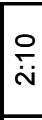 \\
\hline & 芒品 & o & $\infty$ & 1 & 1 & + & 1 & 1 & 1 & 1 & $\cong$ & 이 & 0 & 0 & $r$ & r & 0 & $\infty$ & $\stackrel{10}{\square}$ & \pm \\
\hline & 岳 \# & $\nabla$ & o & 1 & $i$ & + & i & 1 & 1 & 1 & $\nabla$ & $\nabla$ & + & + & + & $\nabla$ & + & $\nabla$ & + & + \\
\hline & 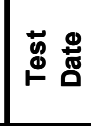 & 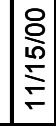 & \begin{tabular}{|l} 
\\
\\
0 \\
0 \\
0
\end{tabular} & 1 & i & $\begin{array}{c}\overline{2} \\
\mathbf{2} \\
\mathbf{2} \\
0\end{array}$ & 1 & ! & 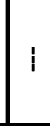 & 1 & 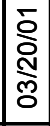 & 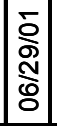 & 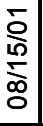 & 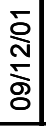 & \begin{tabular}{|}
$\bar{\vdots}$ \\
$\vdots$ \\
$\vdots$ \\
\end{tabular} & 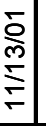 & 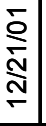 & $\begin{array}{c}\frac{\tilde{O}}{5} \\
\frac{5}{5} \\
\end{array}$ & 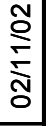 & 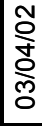 \\
\hline \multirow{2}{*}{ 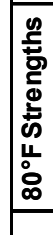 } & \& $\widehat{\overline{\overline{0}}}$ & 过 & : & స్్ & 1 & 1 & 1 & 1 & 1 & 1 & $\mid \begin{array}{c}\hat{n} \\
\end{array}$ & 1 & 1 & 1 & 1 & 1 & 1 & 1 & 1 & 1 \\
\hline & 兽 & $\stackrel{N}{N}$ & $\mid$ a & N & 1 & 1 & 1 & ! & 1 & I & 剚 & 11 & 1 & 1 & 11 & $i$ & 1 & 1 & 1 & i \\
\hline & $\delta^{\circ \overline{0}}$ & $!$ & \begin{tabular}{|l|l|l}
$\stackrel{+}{\circ}$ \\
\end{tabular} & 1 & $!$ & $!$ & 1 & 1 & ! & 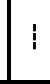 & 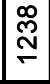 & 1 & 1 & 1 & 1 & | & 1 & 1 & 1 & 1 \\
\hline & 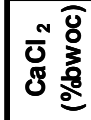 & 1 & - & 1 & 1 & 1 & 1 & 1 & 1 & 1 & $1-$ & 1 & 1 & 1 & 1 & i & 1 & 1 & 1 & 1 \\
\hline & 菒 $\underline{\underline{\underline{1}}}$ & 1 & A & 1 & 1 & 1 & 1 & 1 & 1 & 1 & $\mathbb{N}$ & 1 & 1 & 1 & 1 & 1 & 1 & 1 & 1 & 1 \\
\hline & 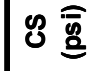 & 1 & $\hat{2}$ & 1 & 1 & 界 & 1 & ; & 1 & i & 1 & i & 1 & 1 & 1 & ! & 1 & 1 & 1 & 1 \\
\hline & 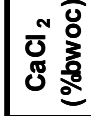 & 1 & $\sim$ & 1 & 1 & $|\sim|$ & 1 & ! & I & 1 & $i$ & | & 1 & 1 & 1 & ! & 1 & 1 & 11 & 1 \\
\hline & 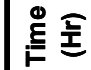 & 1 & $\stackrel{\sim}{\sim}$ & 1 & 1 & A & 1 & 1 & 1 & 1 & 1 & 1 & 1 & 1 & 1 & 1 & 1 & 1 & 1 & 1 \\
\hline \multirow{4}{*}{ 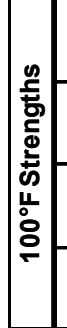 } & \& $\overline{\overline{0}}$ & : & \begin{tabular}{|l|} 
\\
o \\
N
\end{tabular} & 1 & 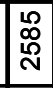 & \begin{tabular}{|c|}
$\hat{N}$ \\
$\stackrel{్}{N}$
\end{tabular} & 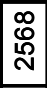 & 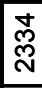 & 怘 & 芯 & 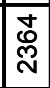 & 1 & 1 & 1 & 1 & 1 & 1 & 1 & 1 & 1 \\
\hline & 茥空 & 1 & A & 1 & N & $\mathbf{N}$ & A & N & N & I & I & 1 & 1 & 1 & 1 & i & 1 & 1 & 1 & 1 \\
\hline & \& & 1 & 兽 & 1 & 1 & $\stackrel{\mathbb{N}}{\mathbf{N}}$ & $\bar{\delta}$ & 1 & 1 & 1 & $\frac{0}{\sigma}$ & ! & 1 & 1 & 1 & 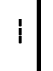 & 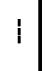 & 1 & 1 & 1 \\
\hline & 皇 & 1 & $\infty$ & 1 & 1 & $\infty$ & $\infty$ & i & 1 & 1 & $\infty$ & I & 1 & 1 & 1 & ! & I & 1 & 1 & 1 \\
\hline \multicolumn{2}{|c|}{ 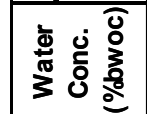 } & $\begin{array}{l}0 \\
\dot{g} \\
\dot{q}\end{array}$ & $\mid \begin{array}{l}0 \\
\dot{g} \\
\dot{q}\end{array}$ & $\begin{array}{l}\stackrel{\circ}{\dot{\theta}} \\
\dot{g}\end{array}$ & $\begin{array}{l}\dot{0} \\
\dot{q}\end{array}$ & $\begin{array}{l}0 \\
\dot{\varphi} \\
\dot{q}\end{array}$ & $\begin{array}{l}0 \\
\dot{g} \\
\dot{q}\end{array}$ & $\begin{array}{l}0 \\
\dot{q}\end{array}$ & $\begin{array}{l}\stackrel{0}{0} \\
\dot{q}\end{array}$ & $\begin{array}{l}O \\
\dot{q}\end{array}$ & $\begin{array}{l}0 \\
\dot{\varphi} \\
\dot{q}\end{array}$ & $\begin{array}{l}0 \\
0 \\
\dot{q} \\
\end{array}$ & $\begin{array}{l}0 \\
\dot{\phi} \\
\dot{q}\end{array}$ & $\begin{array}{l}0 \\
\dot{b} \\
\dot{t}\end{array}$ & $\begin{array}{l}\circ \\
\dot{g}\end{array}$ & 웅 & $\begin{array}{l}0 \\
\dot{g}\end{array}$ & $\begin{array}{l}0 \\
\dot{b} \\
\dot{q}\end{array}$ & $\begin{array}{l}0 \\
\dot{g} \\
\end{array}$ & $\begin{array}{l}0 \\
\dot{\sigma} \\
\dot{f}\end{array}$ \\
\hline & 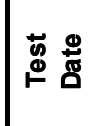 & 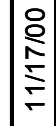 & 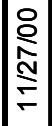 & 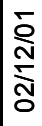 & 怘 & $\mid \begin{array}{c}\bar{\delta} \\
\frac{1}{2} \\
\vdots \\
0\end{array}$ & 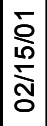 & & 六 & 交 & $\mid$ & $\mid$ &  & 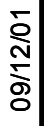 & $\mid \begin{array}{c}\overline{0} \\
0 \\
\overline{0} \\
\end{array}$ & $\begin{array}{c}\frac{5}{2} \\
\stackrel{m}{\Sigma} \\
\end{array}$ & 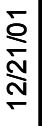 & 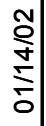 & 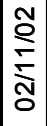 & 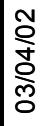 \\
\hline & 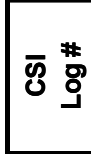 & 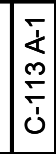 & 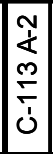 & $\frac{N}{\frac{N}{2}}$ & 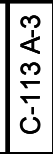 & 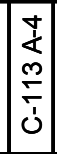 & 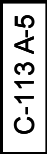 & $\frac{10}{\frac{1}{4}}$ & 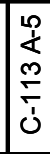 & 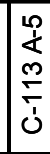 & 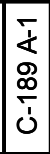 & 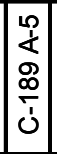 & 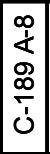 & 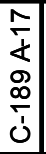 & 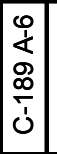 & 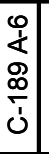 & 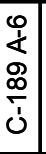 & \begin{tabular}{l|}
$\bar{\tau}$ \\
$\bar{d}$ \\
$\infty$ \\
$\bar{\delta}$ \\
$\bar{u}$
\end{tabular} & 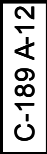 & 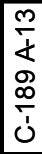 \\
\hline & 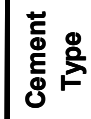 & $\begin{array}{l}\varangle \\
\infty \\
0 \\
\frac{\pi}{0} \\
\end{array}$ & \begin{tabular}{|l|} 
\\
0 \\
0 \\
0 \\
0 \\
0 \\
\end{tabular} & $\begin{array}{l}\frac{\pi}{0} \\
0 \\
0 \\
0 \\
0\end{array}$ & $\begin{array}{l}\varangle \\
\infty \\
0 \\
0 \\
0 \\
\end{array}$ & $\begin{array}{l}\alpha \\
\infty \\
0 \\
\sigma \\
0\end{array}$ & $\begin{array}{l}\varangle \\
0 \\
0 \\
0 \\
0 \\
\end{array}$ & & $\begin{array}{l}\varangle \\
\infty \\
0 \\
0 \\
0 \\
0\end{array}$ & $\begin{array}{l}\varangle \\
w \\
0 \\
0 \\
0\end{array}$ & \begin{tabular}{|l|} 
\\
$\infty$ \\
0 \\
0 \\
0 \\
\end{tabular} & \begin{tabular}{|l|} 
\\
0 \\
0 \\
$\frac{\pi}{0}$ \\
0
\end{tabular} & \begin{tabular}{|l|} 
\\
0
\end{tabular} & \begin{tabular}{|l|} 
\\
0 \\
0 \\
0 \\
0
\end{tabular} & \begin{tabular}{|l|} 
\\
$\infty$ \\
0 \\
$\frac{\pi}{0}$ \\
0
\end{tabular} & & $\begin{array}{l}\frac{\pi}{\infty} \\
0 \\
\frac{\pi}{0} \\
\end{array}$ & & & $\begin{array}{l}\frac{\pi}{\infty} \\
0 \\
\frac{\pi}{0} \\
0\end{array}$ \\
\hline
\end{tabular}




\section{Appendix B-Laboratory Procedures for Foamed Cement}

The working draft of ISO 10426-4 ${ }^{1}$ outlines the recommended practices for the atmospheric generation and testing of foamed cement slurries and their corresponding unfoamed base slurries. The procedures discussed in this appendix and used for this project were borrowed from ISO 10426-4.

\section{B.1 Preparing Unfoamed Base Slurry}

\section{B.1.1 Calculation of Base Cement With and Without Surfactants}

Because the final slurry for foamed cement contains surfactant(s), these materials cannot be added to the base slurry for initial mixing. This will require that the density of the base slurry be adjusted to compensate for the later addition of the surfactant(s) prior to foaming.

Example: $\quad$ Slurry Design: Class G Cement + 0.2 gal/sk Surfactant

\begin{tabular}{|c|c|c|}
\hline Base slurry density & $14.5 \mathrm{lb} / \mathrm{gal}$ & \\
\hline Surfactant weight & 10 lb/gal & \\
\hline Base Slurry Calculations: & Weight & Volume \\
\hline Cement & $94 \mathrm{lb}$ & $\overline{3.59 \mathrm{gal}}$ \\
\hline Surfactant & $2 \mathrm{lb}(0.2 \mathrm{gal} * 10 \mathrm{lb} / \mathrm{gal})$ & $0.2 \mathrm{gal}$ \\
\hline Water & $\underline{55.39 \mathrm{lb}}$ & $6.65 \mathrm{gal}$ \\
\hline Total & $\overline{151.39 \mathrm{lb}}$ & $\overline{10.44 \mathrm{gal}}$ \\
\hline
\end{tabular}

Calculation of True Weight \% Contributions:

$\begin{array}{ll}\text { Cement } & 62.1 \% \\ \text { Surfactant } & 1.3 \% \\ \text { Water } & 36.6 \%\end{array}$

$\begin{array}{cll}\text { Slurry without Surfactants: } & \frac{\text { Weight }}{94 \mathrm{lb}} & \underline{\text { Volume }} \\ \text { Cement } & \underline{55.39 \mathrm{lb}} & \underline{6.65 \mathrm{gal}} \\ \text { Water } & \underline{149.39 \mathrm{lb}} & 10.24 \mathrm{gal} \\ \text { Total } & \end{array}$

Slurry Density without Surfactants: $149.39 / 10.24=14.59 \mathrm{lb} / \mathrm{gal}$

\section{B.2 Equipment}

\section{B.2.1 Blender Container}

A special blending container is required for preparing foamed cement at ambient pressure in the laboratory. (A typical blending container is shown in Figure B.1) The blending container is similar to the one used for standard slurry preparation except that it has a threaded cap with an O-ring seal. The cap has a small hole (approx. 3/4-in. diameter) in the center fitted with a removable plug that has an O-ring seal. 


\section{B.2.2 Multi-Blade Assembly}

The multi-blade assembly is what is used during this project. The multi-blade or stackedblade assembly is constructed of a series of assemblies, each blade corresponding to the requirements of ISO $10426-2^{2}$, clause 5 . The assembly consists of five (5) standard blades attached to a central shaft, and spaced equally throughout the mixing container. A typical assembly is shown in Figure B.1.

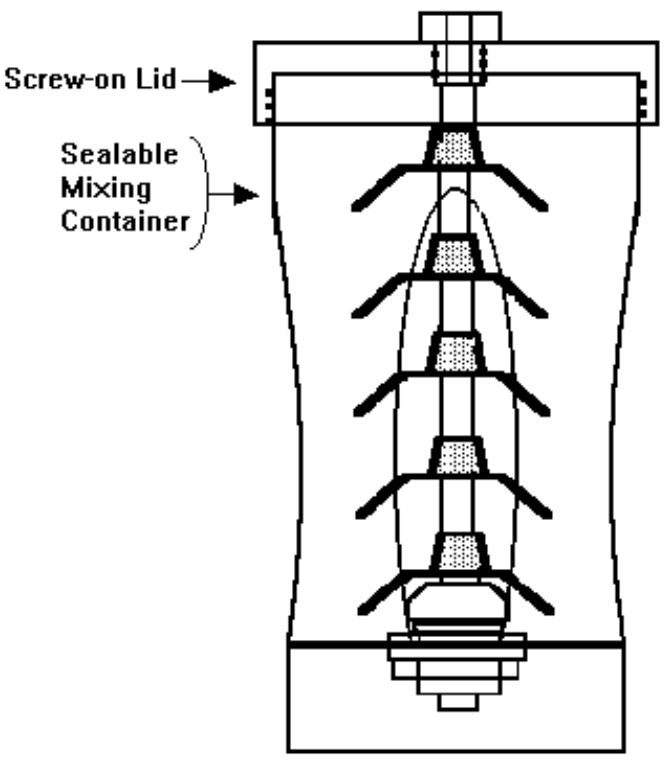

Fig. B.1-Example of a typical blending container

\section{B.3 Container Volume}

Accurate determination of the volume of the blending container is critical to this procedure. The calculations for slurry volume and foamed cement density are based on this volume determination. Weigh the clean, dry, blending container (including mixing assembly, screw-on lid and screw-in plug for the lid). Remove the screw-on lid from the mixing container and then remove the screw-in plug from the lid. Fill the mixing container with water and then screw the lid on tightly. Pour additional water into the hole in the lid for the plug until the container is completely filled, and then screw the plug tightly into the lid. Wipe the excess water that exits from the plug's vent hole, and then weigh the container again. The weight of the water inside the container is then divided by the density of the water to determine an accurate volume for the mixing container.

\section{B.4 Preparing Base Cement Slurry}

This method assumes that the base slurry as described in Section B.1.1 is being prepared in a separate mixing container, and this slurry is then to be weighed into the mixing container described in Section B.2.1. To prepare sufficient volume may require multiple mixes with the standard mixing procedure. 
Base slurries containing all additives except foaming surfactant(s) should be prepared according to ISO $10426-2^{2}$,clause 5 . When possible, the temperature of the cement sample, additives, and mix water should be within $\pm 2{ }^{\circ} \mathrm{C}\left(3^{\circ} \mathrm{F}\right)$ of the respective temperatures recorded from the well site. The temperature of the mixing container should approximate that of the mix water being used in the slurry design. The mixing device should be calibrated annually to a tolerance of $\pm 3.3 \mathrm{rev} / \mathrm{s}(200 \mathrm{rpm})$ at $66.7 \mathrm{rev} / \mathrm{s}(4,000$ $\mathrm{rpm})$ and $\pm 8.3 \mathrm{rev} / \mathrm{s}(500 \mathrm{rpm})$ at $200 \mathrm{rev} / \mathrm{s}(12,000 \mathrm{rpm})$.

As required, the density of the unfoamed cement slurry can be determined by methods found in ISO 10426-2 $2^{2}$, clause 6 .

\section{B.5 Determining Slurry Volumes and Weights}

\section{B.5.1 Slurry Volume}

Determine the volume of unfoamed cement slurry to be mixed. The total volume of unfoamed cement slurry should include the volume of the surfactant(s) to be added to the slurry. The surfactant(s) is to be added after the initial mixing of the base slurry. The volume of unfoamed slurry to be placed in the container may be determined by the following procedure.

When it is desired to foam a slurry with a specific amount of gas per unit volume of slurry (foam quality), the resultant density of the foamed slurry must be determined. This can be calculated by Equation 1 .

$$
F D=(100-\% G) \div 100 \times U F D S
$$

Where: $\quad$ FD $=\quad$ Foamed density of the slurry

$\% \mathrm{G}=$ Percentage of gas in final foamed slurry

UFDS $=\quad$ Unfoamed slurry density with surfactant(s)

When a desired foamed slurry density is known or after calculating it with Equation 1, determine the grams of cement slurry including surfactant(s) that is to be placed into the foam blender to prepare the foamed slurry. This can be calculated by Equation 2 .

$$
G U F S=C V \times F D
$$

Where: $\quad$ GUFS $=\quad$ Grams of unfoamed slurry including surfactant(s) to be

$$
\begin{array}{lll}
\mathrm{CV} & = & \text { Container volume of foam mixer }(\mathrm{mL}) \\
\mathrm{FD} & = & \text { Foamed density of the slurry }(\mathrm{g} / \mathrm{mL})
\end{array}
$$

Example: Container volume $\quad=1170 \mathrm{~mL}$

$\begin{array}{llll}\text { Base slurry density } & = & 14.5 \mathrm{lb} / \mathrm{gal}(1.74 \mathrm{~g} / \mathrm{mL}) \\ \text { Foamed cement density } & = & 10.0 \mathrm{lb} / \mathrm{gal}(1.2 \mathrm{~g} / \mathrm{mL}) \\ \text { Unfoamed slurry weight } & = & 1170 \mathrm{~mL} \times 1.2 \mathrm{~g} / \mathrm{mL}=1404 \mathrm{~g}\end{array}$




\section{B.5.2 Surfactant(s) and Slurry Weight}

The surfactant(s) weight is determined by taking the unfoamed slurry weight and multiplying by the percent by weight of surfactant(s). The slurry weight is determined by taking the unfoamed slurry weight and subtracting the surfactant(s) weight. This can be calculated by Equation 4 .

$$
G S=\text { GUFS } \times(\% \text { Surfactant } / 100)
$$

Where: $\quad$ GS $=$ Grams of surfactants (total) to place into the foam mixer with the unfoamed slurry without surfactant(s) GUFS $=\quad$ Total grams unfoamed slurry prepared in Section B.1

$$
G U S M=G U F S-G S
$$

Where: $\quad$ GUSM $=\quad$ Grams of unfoamed slurry without surfactant(s) to be placed into the mixer.

$\begin{array}{llll}\text { Example: } \begin{array}{lll}\text { Unfoamed slurry weight } \\ \text { Percent by weight of surfactant }\end{array} & \begin{array}{l}= \\ \text { Surfactant weight }\end{array} & 1.3 \% & \\ \text { Slurry weight } & = & 1404.1 \times 0.013= & 18.5 \mathrm{~g} \\ & & 1404.1-18.5= & 1385.6 \mathrm{~g}\end{array}$

\section{B.6 Preparing the Atmospheric Foamed Slurry}

Based on the volume calculated in Section B.5.1, weigh the appropriate amount of the prepared slurry into the special mixing container. Add the calculated amount of surfactant(s). The final weight of the cement slurry and added surfactant(s) should be checked against the final desired base slurry density. Before foaming, verify that the total weight of the slurry and added surfactant(s) corresponds to the weight calculated in Section B.5.2.

\section{B.6.1 Generating a Foamed Cement}

Make sure the mixing container is sealed. Using the blade assembly described in Section B.2.2, the slurry should be mixed at the $12,000 \mathrm{rpm}$ setting for 15 seconds. Because of the increase in slurry volume and viscosity, the maximum rpm of the blender could be less than 12,000 rpm. The maximum attainable rpm will depend on the power of the blender, slurry density, and foam quality. Record and report the final rpm of the mixer.

During the mixing, there will be a noticeable change in the sound (pitch) from the blender. After mixing, there may be some slight pressure in the mixing container because of temperature increases and energy imparted to the foam during the foaming process. Be careful when removing the top of the mixing container. After mixing, open the sampling port or container lid, and verify that the slurry completely fills the slurry-mixing container. If the slurry does not fill the mixing container at the end of the 15 -second 
mixing, it is doubtful the slurry will foam properly under field conditions. The slurry should be redesigned.

\section{B.7 Atmospheric Testing of Foamed Cement Slurries}

Because of the high air entrainment in a foamed cement slurry, it is necessary to modify some of the standard testing procedures to prevent obtaining erroneous test results.

\section{B.7.1 Determining Foamed Slurry Density}

The density of the foamed slurry should be determined by pouring it into a container with a large open top that has a known volume when completely filled. Weigh the container, pour the foamed slurry into the container, and level the top with a straight blade. Wipe the outside of the container clean, and weigh the container with the foamed slurry. The density of the foamed slurry in the container is determined by dividing the slurry mass by the container volume and converting to the appropriate density units.

NOTE: Downhole densities may be different than designed values depending on pressure and temperature conditions. Special software is used to predict downhole densities.

\section{B.7.2 Determining Slurry Stability}

\section{B.7.2.1 Unset Slurry Stability}

Evaluate the foam stability by pouring a sample of the foamed cement slurry into a container or graduated cylinder for 2 hours of continued evaluation. Cover or seal the top of the container to prevent drying or dehydration of the sample. Since the main purpose of this test is to check for settling and stability in the foamed slurry, the visual appearance of the foamed slurry (such as free fluid, settling, or bubbles concentrated in a specific area) must be noted. If desired, density measurements may be made of the foam at multiple locations in the cylinder after the 2-hour period. To determine the density of the slurry at various locations in the cylinder, a large syringe with a Tygon tube on it can be used to remove small portions from the top, middle, and bottom. The removed slurry can then be transferred to a smaller graduated cylinder to determine the weight of a known volume of the slurry. From there, the specific gravity and density can be determined.

Pour the foamed slurry into a standard $250-\mathrm{mL}$ graduated cylinder that is used for freefluid testing. Cover the top of the cylinder to prevent dehydration, place it onto the counter-top, and visually examine it during the 2-hour period. The cylinder cannot be cured at temperatures above the ambient temperature at which the foamed slurry was prepared because an increase in temperature will increase the bubble size and may have an effect on the slurry stability.

\section{B.7.2.2 Set Slurry Stability}

Check foam stability by curing samples until they are set for density gradient measurement throughout the sample. These may be cured in non-greased, covered 50.8$\mathrm{mm}$ (2-in.) diameter, 101.6-mm (4-in.) tall cylinders or any appropriate covered container. Use of grease or other mold-release agents should be avoided as these 
materials may affect the stability of the foamed cement.

Cut or break the samples into sections, mark them from the top to the bottom, and measure the specific gravity of each section. The specimen should not be cut with a saw that uses water. The use of water may cause the specimen to absorb water and change the density of the specimen. Large variations in density from sample top to bottom are an indication of instability. When determining the specific gravity by Archimedes principal, it is recommended that a beaker of fresh water be placed on a scale and tared. The specimen is placed into a loop of fine string (or thread) and suspended in the water for the first measurement for determining the volume of the specimen (V). The volume of the specimen $(\mathrm{mL})$ will be equal to the weight of the water displaced by the specimen when suspended in the water. The weight of the specimen being suspended in the water must be determined quickly to prevent the specimen from absorbing water and giving erroneous results. The specimen is then lowered to rest on the bottom of the beaker of water to obtain the actual weight of the specimen (W). The specific gravity (SG) is then determined by dividing the weight, $\mathrm{W}$ (in grams) by volume, $\mathrm{V}$ (in $\mathrm{mL}$ ). The slurry density can also be determined $(\mathrm{SG} \times 8.33=\mathrm{lb} / \mathrm{gal})$.

Signs of foam instability include the following:

- More than a trace of free fluid.

- Bubble breakout noted by bubbles appearing on the surface of the sample.

- Excessive gap at the top of the specimen. Minor meniscus effects are normal.

- Visual signs of density segregation as indicated by streaking or light to dark color change from top to bottom.

- Large variations in density from sample top to bottom.

\section{B.7.3 Determining Compressive Strength}

The foamed cement slurry is poured into a curing mold that can be sealed. The sealing lid prevents the foamed slurry from expanding out of the curing mold as it is heated. This expansion can result in an undesired density decrease. The mold can be a standard 50.8mm (2-in.) cube mold with a cover clamped to the top.

The sealed mold containing the foamed cement slurry is then placed into an atmospheric water bath, cured, and the strength is determined as specified by API. The temperature is normally limited to approximately $65^{\circ} \mathrm{C}\left(149^{\circ} \mathrm{F}\right)$, but can sometimes be increased to $90^{\circ} \mathrm{C}$ $\left(194^{\circ} \mathrm{F}\right)$ if there is sufficient seal to prevent the slurry from expanding out of the curing mold.

\section{B.8 Determining Other Tests on Base Unfoamed Slurry}

A slurry that is foamed at atmospheric pressure should not be tested under pressure. Applying pressure to a foamed slurry prepared at atmospheric pressure will compress the foam, changing the density and gas ratio. This can also allow contamination when tested in a HPHT consistometer for thickening time.

For the following tests, the base unfoamed slurry without the surfactant(s) is prepared according to ISO $10426-2^{2}$, clause 5 . After the slurry is prepared, the mixer is stopped 
and the surfactant(s) added and stirred gently with a spatula to distribute it uniformly in the slurry. It is recommended the slurry be transferred gently from the mixing container to a beaker and back three times to ensure a uniform distribution. The use of a small amount of material for preventing/breaking air entrainment in slurries that are not foamed is permitted for these tests. Materials to prevent/break air entrainment should not be used in any foamed slurries.

\section{B.8.1 Determining Thickening Time}

Since the surfactant(s) will affect the thickening time, and the foam itself does not affect the thickening time of a cement slurry, the thickening time test is normally performed using a standard HPHT consistometer on the base unfoamed cement slurry containing the surfactant(s).

The thickening time test of the unfoamed slurry containing the surfactant(s) will be performed using the procedures in ISO 10426-2 $2^{2}$, clause 9.

\section{B.8.2 Determining Fluid Loss}

Fluid-loss tests performed with a foamed cement prepared at atmospheric pressure will not yield reliable results. The fluid loss values obtained from a foamed cement slurry will be slightly less than that of the base unfoamed cement slurry. The fluid loss of the base unfoamed cement is normally used as an indication of the fluid loss of the foamed cement slurry.

The static fluid-loss test of the unfoamed slurry containing the surfactant(s) is performed using the procedures in ISO $10426-2^{2}$, clause 10.

\section{B.8.3 Determining Rheological Properties}

With the concentration of gas in a foamed slurry changing continuously during pumping of the job, it is impractical to perform rheological testing at all the foam quality concentrations that are needed to model the frictional pressures during pumping of a foamed slurry. Use of a rotational viscometer will result in separation of the gas from the slurry, causing erroneous results. Correlations can be used to convert the rheological properties of the base unfoamed slurry to that of a foamed cement with varying foam qualities to simulate the job.

The rheological test of the unfoamed slurry containing the surfactant(s) is performed using the procedures in ISO $10426-2^{2}$, clause 12.

\section{References}

1 ISO 10426-4: "Petroleum and Natural Gas Industries_-Cements and Materials for Well Cementing, Part 4: Recommended Practice for Atmospheric Foam Cement Slurry Preparation," working draft 2001.

2 ISO 10426-2: "Petroleum and Natural Gas Industries_-Cements and Materials for Well Cementing, Part 2: Recommended Practice for Testing of Well Cements," 1998. 